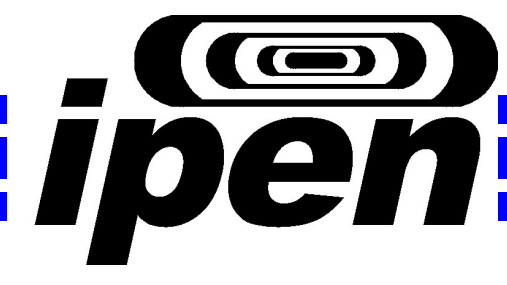

AUTARQUIA ASSOCIADA À UNIVERSIDADE DE SÃO PAULO

\title{
GESTÃO DE REJEITOS RADIOATIVOS EM SERVIÇOS DE MEDICINA NUCLEAR
}

\author{
ALEX BARBOZA
}

Dissertação apresentada como parte dos requisitos para obtenção do Grau de Mestre em Ciências na Área de Tecnologia Nuclear Aplicações

Orientador:

Dr. José Cláudio Dellamano

SÃO PAULO 


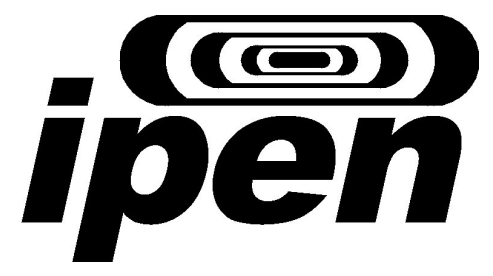

AUTARQUIA ASSOCIADA À UNIVERSIDADE DE SÃO PAULO

\title{
GESTÃO DE REJEITOS RADIOATIVOS EM SERVIÇOS DE MEDICINA NUCLEAR
}

\author{
ALEX BARBOZA
}

\author{
Dissertação apresentada como \\ parte dos requisitos para obtenção \\ do Grau de Mestre em Ciências na \\ Área de Tecnologia Nuclear - \\ Aplicações \\ Orientador: \\ Dr. José Cláudio Dellamano
}




\section{AGRADECIMENTOS}

Ao Dr. José Claudio Dellamano, pela orientação, dedicação e confiança.

Ao Dr. Roberto Vicente, pelo incentivo, discussões e sugestões.

Ao Dr. David Serson, pelo incentivo.

Aos colegas do Laboratório de Rejeitos Radioativos, pela colaboração. 
À família e amigos. 


\title{
GESTÃO DE REJEITOS RADIOATIVOS EM SERVIÇOS DE MEDICINA NUCLEAR
}

\author{
Alex Barboza
}

RESUMO

O uso de radioisótopos em medicina nuclear, seja para terapia ou diagnóstico, gera rejeitos radioativos. A quantidade e características desses rejeitos variam em função da quantidade de pacientes atendidos, do tipo de procedimento realizado e do radioisótopo utilizado. A gestão desses rejeitos abrange todas as atividades técnicas e administrativas envolvidas no manuseio dos rejeitos, desde a sua geração até seu destino final e deve ser considerada e planejada desde o momento da implementação do serviço de medicina nuclear. $\mathrm{O}$ objetivo principal da gestão de rejeitos radioativos é garantir a proteção do homem e a preservação do meio ambiente. $O$ regulamento que estabelece as bases para a boa gestão dos rejeitos radioativos foi elaborado pela Comissão Nacional de Energia Nuclear, em 1985. Trata-se da Norma CNEN-NE-6.05 "Gerência de rejeitos radioativos em instalações radiativas" que embora seja um marco relacionado à gestão dos rejeitos radioativos e ajude em grande parte no papel de orientar no projeto de um sistema de gestão em instalações radioativas de usuários de radioisótopos, aborda os tópicos de forma generalizada e não considera aspectos particulares das diferentes instalações, como é o caso dos serviços de medicina nuclear. $O$ presente trabalho pretende colaborar com referências que forneçam orientações sobre como cumprir as exigências regulatórias e descrever o sistema de gerência de rejeitos radioativos em serviços de medicina nuclear. 


\title{
GESTÃO DE REJEITOS RADIOATIVOS EM SERVIÇOS DE MEDICINA NUCLEAR
}

\author{
Alex Barboza
}

\begin{abstract}
Radioisotope applications in nuclear medicine services, for diagnosis and therapy, generate radioactive wastes. The general characteristics and the amount of wastes that are generated in each facility are function of the number of patients treated, the procedures adopted, and the radioisotopes used. The management of these wastes embraces every technical and administrative activity necessary to handle the wastes, from the moment of their generation, till their final disposal, must be planned before the nuclear medicine facility is commissioned, and aims at assuring people safety and environmental protection. The regulatory framework was established in 1985, when the National Commission on Nuclear Energy issued the regulation CNEN-NE-6.05 - 'Radioactive waste management in radioactive facilities'. Although the objective of that regulation was to set up the rules for the operation of a radioactive waste management system, many requirements were broadly or vaguely defined making it difficult to ascertain compliance in specific facilities. The objective of the present dissertation is to describe the radioactive waste management system in a nuclear medicine facility and provide guidance on how to comply with regulatory requirements.
\end{abstract}




\section{SUMÁRIO}

Página

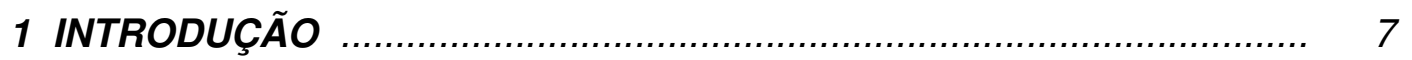

1.1 Geração de energia .................................................................

1.2 Aplicações Industriais .............................................................. 8

1.3 Aplicações na área médica .............................................................. 10

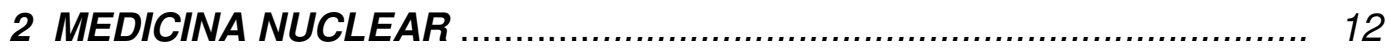

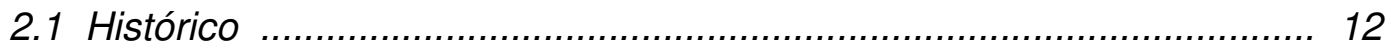

2.2 A produção da imagem na Medicina Nuclear ..................................... 15

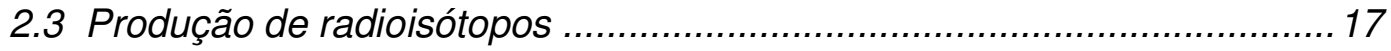

2.4 Classificação dos Serviços de Medicina Nuclear .................................... 22

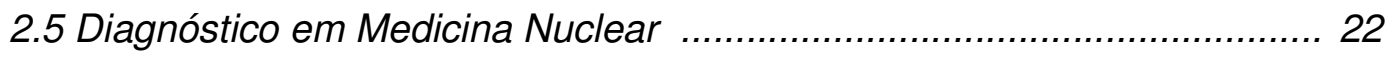

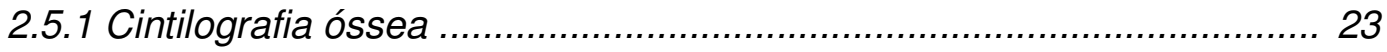

2.5.2 Estudos cardiovasculares ........................................................ 23

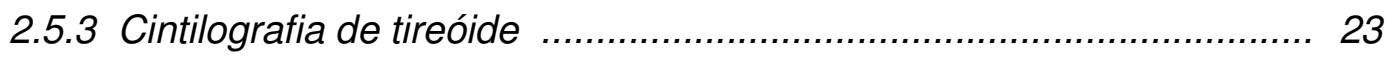

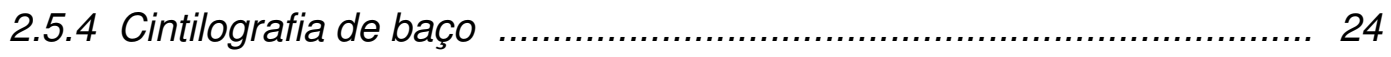

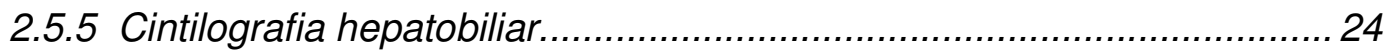

2.5.6 Cintilografia de ventilação e perfusão pulmonar.................................... 25

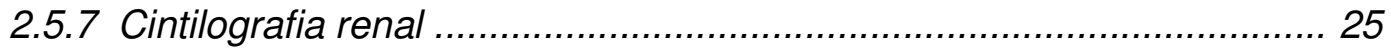

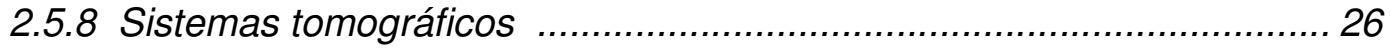

3 REJEITOS RADIOATIVOS

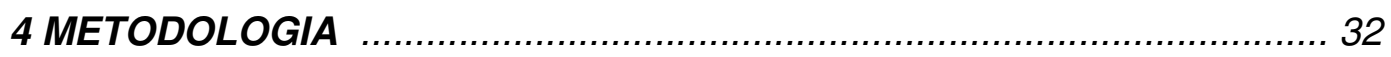

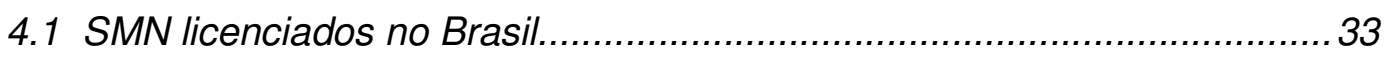

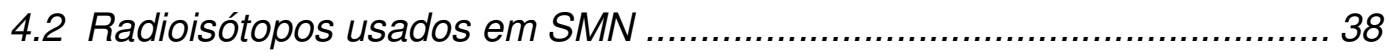

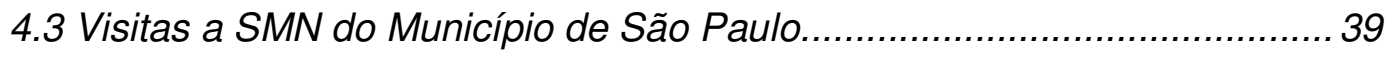

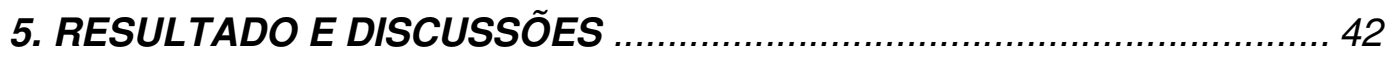

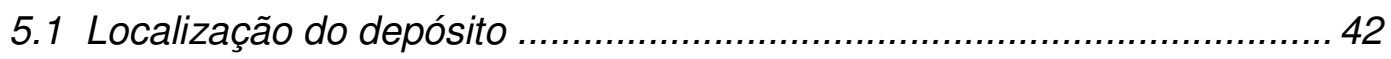

5.2 Transporte interno de rejeitos radioativos ................................................ 45

5.3 Sinalização e fixação de procedimentos ............................................. 47

5.4 Segurança física do depósito de rejeitos radioativos............................... 49

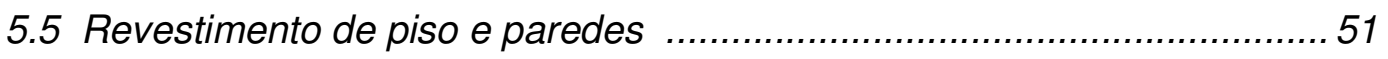

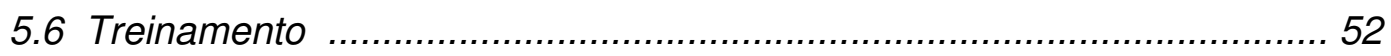

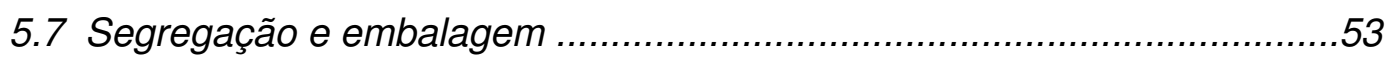




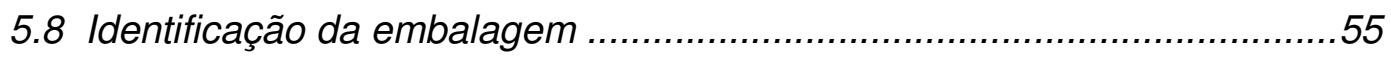

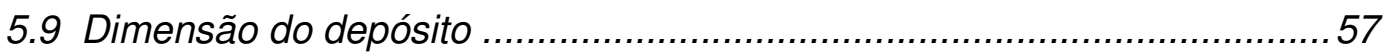

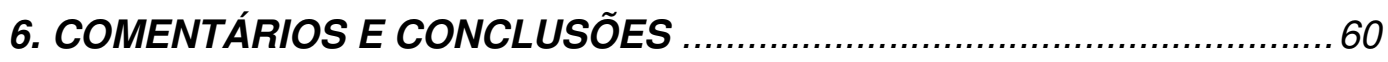

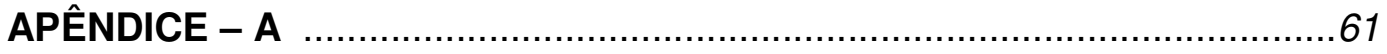

7. REFERÊNCIAS BIBLIOGRÁFICAS .......................................... 73 


\section{INTRODUÇÃO}

Poucas áreas da ciência tiveram um desenvolvimento tão rápido e um campo de aplicação tão abrangente quanto ao da energia nuclear. Aplicações que beneficiam toda a sociedade e que vão da geração de energia nucleoelétrica, controle de qualidade na área industrial, diagnóstico e tratamento de doenças até avanços nas áreas científica e agrícola. A seguir serão abordados alguns detalhes dessas aplicações.

\subsection{Geração de Energia}

A primeira forma de matriz energética foi o combustível fóssil. O aumento do domínio e do uso da energia contida nesses combustíveis fósseis, sua abundância e baixo custo, tornaram-no a principal matriz energética desde a sua origem até os dias de hoje. No entanto, por se tratar de uma energia finita e por despertar preocupações ambientais relativas ao seu uso, forçaram a indústria a olhar para alternativas de matrizes energéticas.

Hoje, o estudo de alternativas energéticas tem por premissa o desenvolvimento sustentável, que é a relação harmoniosa entre os agentes econômicos e a natureza [1].

Empreendimentos energéticos de qualquer natureza, hidroelétrica, termelétrica ou termonuclear, em maior ou menor grau, causam interferências ao meio ambiente. Embora todos os tipos de geração de energia, de alguma forma, tragam impactos negativos ao meio ambiente, a energia precisa continuar sendo gerada para poder atender ao crescimento da população e suas necessidades de desenvolvimento e sobrevivência.

O que tem sido avaliado quanto à escolha para exploração e utilização de uma matriz energética é a utilização de fontes viáveis economicamente, que consigam suprir a demanda energética causando o menor impacto ambiental possível. 
Fontes renováveis de energia, como a eólica e a solar, freqüentemente são apontadas por ambientalistas como uma solução, no entanto, não são capazes de fornecer energia em larga escala, são dispersas, não fornecerem energia de forma contínua e necessitam de uma grande área para sua implantação [2].

$\mathrm{Na}$ avaliação das alternativas viáveis de matriz energética cresce o ímpeto para uma revitalização nuclear. A indústria nuclear ainda tem como principal barreira a fobia nuclear apresentada por parte da opinião pública e alguns grupos ambientalistas, que justificam o temor de possíveis acidentes como o ocorrido em Chernobyl e a "falta de solução" para o problema dos rejeitos radioativos.

Quanto à insegurança das usinas nucleares, deve-se lembrar que Chernobyl foi um acidente previsível que se deu por falha humana, além de ser um modelo primitivo de reator soviético do tipo RMBK, que não possuía vaso de contenção, e que nunca seria licenciado no ocidente.

As usinas que utilizam reator PWR, utilizadas nos Estados Unidos e Brasil, apresentam um histórico de nenhuma morte e nem contaminação externa. São constituídas por estrutura protetora com $1,80 \mathrm{~m}$ de concreto de espessura que não só protege contra a liberação de elementos radioativos para o meio ambiente, mas também protege de possíveis acidentes externos.

As usinas nucleares, por garantirem níveis de segurança aceitáveis e fornecerem uma forma de energia sem emissões de gases que contribuem para o efeito estufa, vêm sendo vistas de forma positiva como uma solução viável para a redução do ritmo das mudanças climáticas [3].

\subsection{Aplicações Industriais}

Dentre as aplicações industriais destacam-se a radioesterilização, a irradiação de alimentos, fios e cabos, a radiografia industrial e, principalmente, o controle de qualidade de processos e produtos.

A radioesterilização é a esterilização de materiais com 0 uso de radiação ionizante. É utilizada para os mais diversos tipos de produtos, como produtos farmacêuticos (gaze, fraldas, cosméticos, seringas e agulhas) e produtos de uso médico (suturas e materiais cirúrgicos em geral). [4] 
No caso de alimentos, a irradiação é realizada para retardar o apodrecimento, principalmente no caso de frutos, para inibir brotamento, principalmente no caso de cebola e batata e também para reduzir ou inibir o crescimento de fungos e microorganismos, como no caso das especiarias. Em todos os casos, a irradiação permite que o alimento tenha uma maior durabilidade, sem perder suas características originais (valor protéico, cor, sabor, aroma), o que contribui no comércio desses produtos, principalmente no caso de exportação [5].

A irradiação de fios e cabos elétricos com feixes de elétrons é realizada para melhorar as propriedades térmicas, elétricas e mecânicas, possibilitando a obtenção de condutores com maior resistência que são utilizados nas indústrias aeronáutica, automobilística, naval e de computação.

A radiografia industrial é um ensaio não destrutivo que usa fontes de radiação para detectar falhas nos materiais ou nas soldas aplicadas durante a fabricação dos mesmos. Esse tipo de ensaio assegura a integridade das estruturas, peças e equipamentos e é um quesito de controle de qualidade exigido no mercado internacional. $O$ ensaio pode ser realizado utilizando-se dois tipos de radiação ionizante: raios $X$ ou raios gama. $O$ ensaio que utiliza os raios gama produzidos por isótopos radioativos é denominado gamagrafia [6].

O controle de processos e produtos é feito por meio de equipamentos, comumente chamados de medidores nucleares, que empregam fontes radioativas para determinação de nível, densidade, espessura, peso, gramatura, etc.

$\mathrm{Na}$ indústria de laminados, como papel, papel alumínio, filme de PVC, a utilização desta técnica garante que todas as folhas tenham a mesma gramatura e espessura. $\mathrm{Na}$ indústria de bebidas, garante que os volumes corretos nas embalagens sejam alcançados. Na construção de estradas são utilizados medidores de densidade e umidade de solos. No setor petrolífero, os medidores nucleares são utilizados na perfilagem de poços de petróleo para a medida e registro da composição dos minérios, de forma contínua, ao longo das paredes de um poço. 


\subsection{Aplicações na área médica}

A medicina foi a área pioneira na aplicação das radiações ionizantes, logo após a descoberta dos raios-X e pode-se dizer que a evolução desta área está associada à própria evolução da tecnologia nuclear.

Atualmente, a medicina faz uso da tecnologia nuclear em três grandes áreas: radiologia, radioterapia e medicina nuclear, tendo cada uma delas suas peculiaridades.

A radiologia engloba todos os diagnósticos por imagem que utilizam equipamentos geradores de raios- $X$ para a produção de radiação artificial $\mathrm{e}$ obtenção de imagens. Entre os procedimentos estão a radiografia convencional e a especializada, como mamografia e tomografia computadorizada.

A radioterapia é a especialidade médica que se ocupa, principalmente, do tratamento oncológico baseado na interação da radiação ionizante com o tumor. Há duas modalidades de radioterapia, de acordo com o posicionamento da fonte em relação ao corpo do paciente, são elas: teleterapia e braquiterapia.

A teleterapia é o tratamento oncológico em que o paciente recebe a radiação de uma fonte externa, posicionada a no mínimo $20 \mathrm{~cm}$ de sua superfície. Os equipamentos utilizados em teleterapia são os aceleradores lineares, máquinas de raios- $X$ e os equipamentos com fontes radioativas, principalmente ${ }^{60} \mathrm{Co}$ e ${ }^{137} \mathrm{Cs}$.

Na braquiterapia, a fonte de radiação é inserida no corpo do paciente, ficando em contato direto com o tumor. Materiais radioativos, geralmente pequenas fontes seladas como tubos de ${ }^{137} \mathrm{Cs}$, sementes de ${ }^{125} \mathrm{I}$ e fios de ${ }^{192} \mathrm{Ir}$, são colocadas junto ao tumor liberando doses de radiação diretamente sobre ele, afetando ao mínimo os órgãos mais próximos e preservando os mais distantes da área do implante.

A Medicina Nuclear é uma especialidade médica que se ocupa das técnicas de diagnóstico e terapia. Para cada uma das técnicas são produzidas e utilizadas substâncias radioativas específicas em forma de fontes abertas que permitem o diagnóstico ou a terapia de um grande número de doenças, especialmente o câncer. O tópico "Medicina Nuclear" será apresentado com mais detalhes devido a sua importância no desenvolvimento do presente trabalho. 
A manipulação do material radioativo nos Serviços de Medicina Nuclear (SMN) gera rejeitos radioativos, os quais devem ser gerenciados de forma segura a fim de proteger o homem e o meio ambiente.

A gerência de rejeitos radioativos é o conjunto de atividades técnicas e administrativas envolvidas desde a coleta, segregação, caracterização, tratamento, acondicionamento, transporte, armazenamento, controle, registro até o destino final.

A NORMA CNEN-NE-6.05, em seu capítulo cinco, apresenta uma série de requisitos para a operação de um sistema de gestão dos rejeitos radioativos, aos quais todas as instalações radiativas licenciadas estão obrigadas a submeterse [7].

A finalidade do presente trabalho é colaborar com referências que forneçam orientações sobre como cumprir as exigências regulatórias descrevendo o sistema de gerência de rejeitos radioativos em SMN. 


\section{MEDICINA NUCLEAR}

A Medicina Nuclear é uma especialidade médica que se ocupa das técnicas de diagnóstico e terapia utilizando substâncias radioativas em forma de fontes abertas. Estas substâncias radioativas são administradas aos pacientes por inalação, via oral ou endovenosa. Para cada uma das técnicas são produzidos e utilizados radiofármacos específicos que permitem o diagnóstico ou terapia de um grande número de doenças, especialmente o câncer.

\subsection{Histórico}

A medicina nuclear foi inserida oficialmente como uma prática de tratamento e diagnóstico médico em 1971, no entanto a sua origem e suas aplicações se deram bem antes. Alguns marcos históricos que compõem a evolução da medicina nuclear são:

- 1896 - Henri Becquerel descobre os "raios" de urânio;

- 1897 - Marie Curie dá o nome de radioatividade para os raios de urânio [8];

- 1897 - J.J. Thompson identifica o elétron;

- 1899 - E. Rutherford, em Cambridge, identifica os raios alfa e beta;

- 1900 - Paul Villard coloca em evidência a existência dos raios gama;

- 1901 - Henri Alexandre Danlos e Eugene Bloch colocam radiação em contato com lesão de pele tuberculosa;

-1902/03 - E. Rutherford e F. Soddy interpretam e descrevem as transformações radioativas, e diferenciam duas formas de radioatividade (alfa ou beta);

- 1903 - Alexander Graham Bell sugere o emprego de fontes radioativas perto de tumores para o tratamento de câncer; 
- 1913 - Frederick Proescher publica o primeiro estudo que faz uso de injeção intravenosa de sustâncias radioativas para o tratamento de diversas doenças;

- 1923 - Georg Von Hevesey registra o primeiro estudo biológico com uso de traçadores radioativos [9];

- 1927 - Geiger e Müller desenvolvem detector de radiações;

- 1930 - Construção do primeiro cíclotron de prótons;

- 1933 - C. Anderson descobre o pósitron;

- 1933 - E. Fermi (Roma) propõe a teoria da radioatividade beta;

- 1934 - O casal Frédéric Joliot e Irène Curie descobre a produção de isótopos artificiais possibilitando novos procedimentos [10];

- 1934 - E. Fermi relata a síntese de radioelementos, por meio do bombardeamento com nêutrons de elementos conhecidos;

- 1935 - Hevesy e Chiewitz sintetizaram ${ }^{32} \mathrm{P}$ como traçador em estudos biológicos;

- 1938 - Realização do primeiro estudo fisiológico da tireóide, utilizando I -131;

- 1939 - O casal Frédéric Joliot e Irène Curie demonstra a importância do iodo radioativo para a exploração da glândula tireóide;

- 1939 - Primeira aplicação terapêutica;

- 1946 - Construção do primeiro reator destinado à produção de radioisótopos;

- 1949 - Inauguração do primeiro centro de medicina nuclear da América Latina no Hospital das Clínicas da Faculdade de Medicina da Universidade de São Paulo - HCFMUSP [11]

- 1950 - Realização de estudos avaliando a possibilidade do uso da radiação proveniente da aniquilação do pósitron para melhorar a qualidade da imagem do cérebro [12];

- 1951 - Reed e Libby constroem um equipamento para transformar as informações fornecidas pelos traçadores em imagens. $O$ equipamento se tratava de um "scanner" com cristal de lodeto de Sódio ou cristal de cintilação, daí o nome cintilografia para as imagens utilizadas em Medicina Nuclear;

- 1951 - Foram publicados artigos internacionais relacionados à gerência de rejeitos radioativos provenientes de SMN [13]; 
- 1952 - Substituição do termo "Medicina Atômica" pelo termo "Medicina Nuclear";

- 1956 - Desenvolvimento de análise imunológica utilizando ${ }^{226} \mathrm{Ra}$;

- 1956 - Instauração da Comissão Nacional de Energia Nuclear - CNEN com o propósito de normatizar e orientar a aplicação da energia nuclear para fins pacíficos no Brasil;

- 1956 - É instituído o Instituto de Energia Atômica - IEA (atual Instituto de Pesquisas Energéticas e Nucleares - IPEN - CNEN/SP);

- 1956 - Instituição do processo de especialização em medicina nuclear na Santa Casa do Rio de Janeiro e no Instituto Assistencial do Servidor do Rio de Janeiro, IASERJ;

- 1959 - Início da produção de ${ }^{131}$ I, no Brasil, pelo Departamento de Radiofarmácia do Instituto de Energia Atômica, medicamento usado para diagnóstico e terapia de doenças da tireóide;

- 1961 - É instituída a Sociedade Brasileira de Biologia e Medicina NuclearSBBMN;

- 1962 - Introdução do ${ }^{99}$ Mo como gerador de ${ }^{99 m} \mathrm{Tc}$ como traçador, possibilitando sua união com diversos fármacos;

- 1963 - Desenvolvimento das atuais gama-câmaras;

- 1964 - É instituída a Associação Latino-Americana de Sociedades de Biologia e Medicina Nuclear - ALASBIMN;

- 1966 - S. Bergson e R. Yalow aperfeiçoam a dosagem de insulina utilizando anticorpos radiomarcados;

- 1968 a 1972 - Desenvolvimento do primeiro programa computacional para imagem tomográfica computadorizada usando tomografia por emissão de pósitron (PET);

- 1968 - A “US Atomic Energy Commission Record of Invention” reconhece como invenção o PC-I, primeiro computador vinculado a detector de imagem para posterior reconstrução das imagens;

- 1970 - Louis Sokoloff e Martin Reivich mostraram que a desoxi-glicose marcada com ${ }^{14} \mathrm{C}$ era capaz de mapear o metabolismo cerebral; 
- 1972 - Godfrey Hounsfield e Allan Cormack constroem o primeiro equipamento de tomografia computadorizada (CT);

- 1973 - Empregado do ${ }^{18} \mathrm{~F}$ para obtenção de imagens em seres humanos;

- 1974 - M.E. Phelps, E.J. Hoffman e colaboradores da Universidade de Washington constroem o primeiro tomógrafo PET para estudos com humanos;

- 1975 - A desoxi-glicose marcada com ${ }^{18} \mathrm{~F}\left(\left[{ }^{18} \mathrm{~F}\right] \mathrm{FDG}\right)$ - foi sintetizada;

- 1975 - Realização, em Paris, da 15a Reunião Internacional de Pesos e Medidas, que adotou duas novas unidades de medida relativas à radioatividade: o Becquerel e o Gray;

- 1979 - Phelps obtém a primeira imagem PET com o FDG [14];

- 1980 - CT se torna o método mais utilizado para o diagnóstico precoce de tumores;

- 1985 - A CNEN estabelece norma sobre Gerência de Rejeitos radioativos em instalações radioativas [7];

- Anos 80 - A medicina nuclear desenvolveu aplicações clínicas empregando PET, e obteve significantes avanços na marcação "in vivo" de processos bioquímicos e genéticos;

- Anos 90 - A PET foi reconhecida como modalidade diagnóstica;

- 2005 - O Brasil adquire seu primeiro PET/CT.

Os registros da Comissão Nacional de Energia Nuclear indicam que no Brasil, atualmente, são realizados cerca de 2,1 milhões de procedimentos médicos com radiofármacos em 282 centros de medicina nuclear [15]. A taxa de crescimento da prestação de serviços com radiofármacos no Brasil é bastante expressiva. $O$ atendimento a pacientes cresceu a uma taxa da ordem de 10\% no ano de 2007 [16].

\subsection{A produção da imagem na Medicina Nuclear}

Cada órgão do corpo interage de forma diferente a produtos químicos. Existe uma gama de substâncias químicas que são absorvidas por órgãos específicos. Estas substâncias quando agregadas a radioisótopos servem como carreadores destes, e o conjunto da substância química com o radioisótopo é 
denominado de radiofármaco. Radiofármaco é definido pela CNEN como "substância radioativa cujas propriedades físicas, químicas e biológicas fazem com que seja apropriada para uso em seres humanos" [17].

A quantidade de radiofármaco administrada a um paciente é a mínima suficiente para obter o resultado terapêutico ou diagnóstico. $O$ paciente não experimenta nenhum desconforto durante o procedimento e depois de pouco tempo, tipicamente, algumas horas, o elemento radioativo é eliminado. $\mathrm{O}$ radiofármaco é incorporado aos processos biológicos naturais e excretado naturalmente.

A intervenção diagnóstica é obtida adquirindo-se imagens da distribuição do radiofármaco no corpo do paciente. A aquisição destas imagens é feita por um equipamento denominado gama câmara.

A gama câmara é o equipamento usado para detectar e localizar a origem espacial de raios gama emitidos pelos radiofármacos administrados no paciente. Ela produz uma imagem dos órgãos do paciente contrastando regiões que emitem poucos raios gama, devido a pouca absorção do radiofármaco, chamadas zonas frias, e regiões com alta absorção, chamadas de zonas quentes.

A gama câmara é constituída por um detector de raios gama (cristais de cintilação à base de Oxiortosilicato de Lutécio, Germanato de Bismuto ou mais freqüentemente de lodeto de Sódio ativado com Tálio) contido numa caixa escura, que transforma a energia dos raios gama em muitos fótons de luz. Estes fótons são intensificados com vários tubos fotomultiplicadores e a eletrônica associada computa as diferentes intensidades medidas. Um colimador de chumbo é usado entre o paciente e o detector para eliminar raios gama que não apresentam direção perpendicular ao detector, torrando a imagem mais nítida. As imagens são produzidas com a ajuda de um computador integrado no equipamento.

Uma gama câmara típica tem uma resolução capaz de captar várias centenas de milhares de fótons por segundo. Para cada um destes fótons ela mede a posição do emissor. Estes dados são então organizados pelo computador numa imagem ou filme. A FIG. 1 apresenta uma imagem obtida em um diagnóstico de tireóide. A região com aspecto mais brilhante indica maior concentração de radioisótopo. 


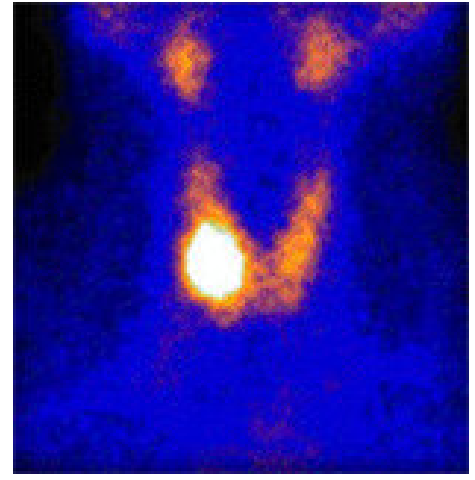

FIGURA 1 - Cintilografia de tireóide [18]

\subsection{Produção de radioisótopos}

Elementos radioativos mantêm uma relação elevada entre o número de prótons e nêutrons. Se a razão nêutrons/prótons $(\mathrm{n} / \mathrm{p})$ for maior daquela da faixa dos isótopos estáveis (excesso de nêutrons), o radioisótopo emitirá partículas $\beta$-. Ao contrário, se a razão $\mathrm{n} / \mathrm{p}$ for menor daquela da faixa dos isótopos estáveis (falta de nêutrons) o radioisótopo emitirá partículas $\beta+$ ou promover a captura eletrônica para transformar um próton em um nêutron.

A FIG. 2, a seguir, apresenta uma tabela de nuclídeos, evidenciando os nuclídeos estáveis que estão concentrados na região central, ladeado, acima e abaixo, por isótopos radioativos.

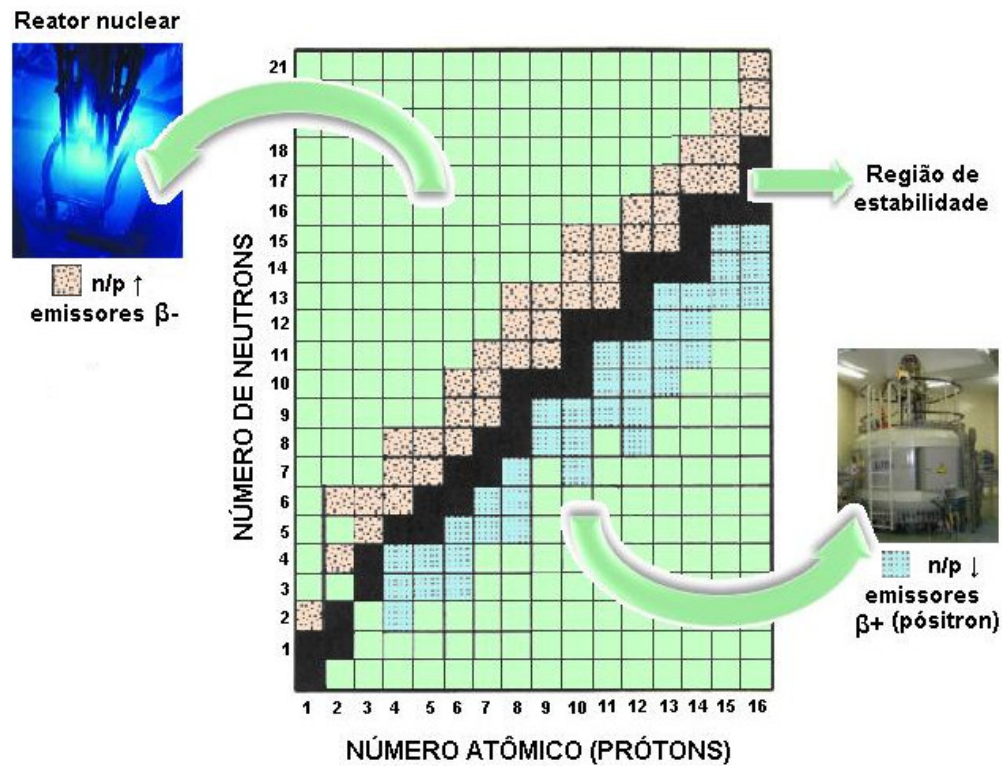

FIGURA 2 - Tabela de nuclídeos 
Todos os radioisótopos de uso clínico em SMN são produzidos em reatores nucleares ou aceleradores (lineares ou cíclotrons).

Os radioisótopos artificiais que apresentam razão $n / p$ alta são produzidos em reatores por captura de nêutrons ou por fissão, já os radioisótopos artificiais que apresentam razão $\mathrm{n} / \mathrm{p}$ baixa são produzidos em aceleradores de partículas (lineares ou cíclotrons). Os aceleradores de partículas são capazes de fornecer energia cinética às partículas, como os prótons, fazendo-os se chocarem violentamente com alvos não radioativos. Quando essas partículas (prótons) são absorvidas pelos núcleos elas aumentam o número de prótons no núcleo diminuindo assim, a razão $n / p$.

A fissão nuclear corresponde à quebra de um núcleo pesado em dois fragmentos de massa aproximadamente iguais. Quando um elemento físsil é inserido no caroço de reator, absorvem nêutrons e sofrem a fissão. As reações a seguir são exemplos da produção de produtos de fissão.

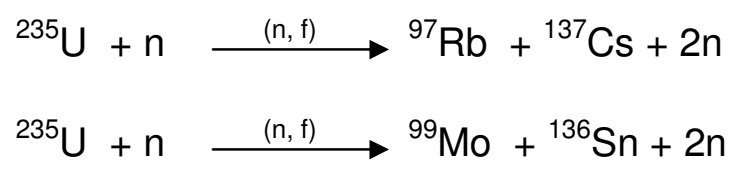

Dentre os radioisótopos de origem na fissão, os de maior interesse no campo da radiofarmácia são: ${ }^{131} \mathrm{I},{ }^{99} \mathrm{Mo}$ e ${ }^{133} \mathrm{Xe}$ os quais podem ser produzidos pela fissão de ${ }^{235} \mathrm{U}$.

Outra técnica de obtenção de radioisótopos em reatores nucleares é por meio da reação de captura de nêutrons. O bombardeio de núcleos com nêutrons de baixa energia origina radionuclídeos ricos em nêutrons que sofrem decaimento beta negativo, conforme exemplo descrito na reação a seguir.

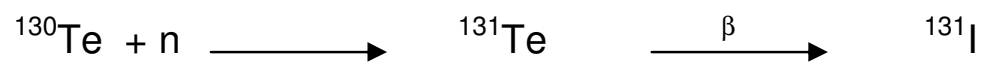

A ativação por nêutrons do molibdênio-98 $\left({ }^{98} \mathrm{Mo}\right)$ foi o primeiro método usado para obter o molibdênio-99 $\left({ }^{99} \mathrm{Mo}\right)$ para o sistema gerador de ${ }^{99} \mathrm{Mo} /{ }^{99 \mathrm{~m}} \mathrm{Tc}$. Hoje em dia para produção em larga escala é utilizado o processo de produção por fissão.

No caso da produção de radioisótopos em aceleradores uma variedade de nuclídeos é utilizada como alvo. Estes são bombardeados por prótons, que os 
tornam nuclídeos instáveis (radionuclídeos) por relação $\mathrm{n} / \mathrm{p}$ baixa, os quais buscam sua estabilidade sofrendo decaimento por pósitron ou captura eletrônica.

A TAB. 1 resume as fontes de produção e as características físicas dos radionuclídeos comumente utilizados na prática clínica em SMN.

TABELA 1 - Radionuclídeos emissores de fóton único usados em SMN [19]

\begin{tabular}{|c|c|c|c|c|c|}
\hline Isótopo & $\begin{array}{c}\text { Decaimento } \\
\text { principal }\end{array}$ & $\begin{array}{c}\mathrm{T}_{1 / 2} \\
\text { física } \\
\text { (dias) }\end{array}$ & $\begin{array}{r}\text { Ener } \\
\text { princ } \\
\text { ab }\end{array}$ & $\begin{array}{l}\text { ia do fóton } \\
\text { pal (keV) e } \\
\text { indância }\end{array}$ & $\begin{array}{c}\text { Método de } \\
\text { produção }\end{array}$ \\
\hline $201 \mathrm{TI}$ & Captura eletrônica & 3,04 & $\begin{array}{r}69-83 \\
135 \\
167\end{array}$ & $\begin{array}{r}(\mathrm{Hg} \mathrm{R}-\mathrm{X}) \\
(2,5 \%) \\
(10 \%)\end{array}$ & Acelerador \\
\hline${ }^{133} \mathrm{Xe}$ & Beta negativo & 5,2 & 81 & $(37 \%)$ & Reator \\
\hline${ }^{131} \mid$ & Beta negativo & 8 & 364 & $(81 \%)$ & Reator \\
\hline${ }^{127} \mathrm{Xe}$ & Captura eletrônica & 36 & $\begin{array}{l}172 \\
203 \\
375\end{array}$ & $\begin{array}{r}(26 \%) \\
(7 \%) \\
(17 \%)\end{array}$ & Acelerador \\
\hline${ }^{123} \mathrm{I}$ & Captura eletrônica & 0,55 & 159 & $(83 \%)$ & Acelerador \\
\hline${ }^{111} \ln$ & Captura eletrônica & 2,8 & $\begin{array}{l}171 \\
245\end{array}$ & $\begin{array}{l}(90 \%) \\
(94 \%)\end{array}$ & Acelerador \\
\hline${ }^{99} \mathrm{Mo}$ & Beta negativo & 2,8 & $\begin{array}{l}740 \\
780\end{array}$ & $\begin{array}{r}(12 \%) \\
(4 \%)\end{array}$ & Reator \\
\hline${ }^{99 m} \mathrm{Te}$ & Transição isomérica & 0,25 & 140 & $(89 \%)$ & (1) \\
\hline${ }^{67} \mathrm{Ga}$ & Captura eletrônica & 3,26 & $\begin{array}{r}93 \\
185 \\
300 \\
395\end{array}$ & $\begin{array}{r}(37 \%) \\
(20 \%) \\
(17 \%) \\
(5 \%)\end{array}$ & Acelerador \\
\hline${ }^{57} \mathrm{Co}$ & Captura eletrônica & 257 & 122 & $(86 \%)$ & Acelerador \\
\hline
\end{tabular}

(1) Método de produção - Gerador de ${ }^{99} \mathrm{Mo}$

Um dos problemas práticos enfrentados pelos SMN é o desejo de utilizar nuclídeos de meia-vida curta e a necessidade de ter os radiofármacos entregues de forma comercial em hospitais e clínicas. Por muito tempo os SMN buscaram radionuclídeos com meia-vida curta, porém a logística de fabricação e transporte impedia o uso desses radionuclídeos. 
Uma forma de contornar esse problema foi o sistema de gerador de radionuclídeo, que consiste na comercialização de um radionuclídeo pai de meiavida longa para a utilização de seu filho de meia-vida curta. Com esta combinação o gerador pode ser comercializado em lugares mais distantes e o radionuclídeo filho ser utilizado para aplicações clínicas sem diminuição significativa em sua atividade. Vários sistemas de geradores foram explorados ao longo dos anos, porém o mais importante é o gerador de ${ }^{99} \mathrm{Mo} /{ }^{99 \mathrm{~m}} \mathrm{Tc}$ que está em toda parte na prática clínica, sendo que cerca de $75 \%$ dos estudos clínicos, atualmente, são realizados com o ${ }^{99 \mathrm{~m}} \mathrm{Tc}$.

Para a produção do sistema gerador de ${ }^{99} \mathrm{Mo} /{ }^{99 m} \mathrm{Tc} \circ{ }^{99} \mathrm{Mo}$ é quimicamente purificado e inserido em uma coluna de troca iônica, que tem a função de reter $0{ }^{99}$ Mo e eluir o ${ }^{99 m} \mathrm{Tc}$.

A coluna carregada é colocada num recipiente de chumbo, com dois tubos inseridos nas extremidades da coluna para permitir sua eluição. Dessa forma o gerador de ${ }^{99 m}$ Tc é comercializado. A FIG. 3 apresenta uma ilustração de um sistema gerador de ${ }^{99} \mathrm{Mo} /{ }^{99 \mathrm{~m}} \mathrm{Tc}$.

O elevado índice de utilização do ${ }^{99 \mathrm{~m}} \mathrm{Tc}$ em SMN é justificado por causa das propriedades físicas e químicas ideais do radioisótopo, tais como: meia-vida física de 6,01 horas; decaimento por emissão de radiação gama pura com fótons de $140 \mathrm{keV}$; e a praticidade da obtenção do radioisótopo a partir de um sistema gerador ${ }^{99} \mathrm{Mo} /{ }^{99 \mathrm{~m}} \mathrm{Tc}$.

A TAB. 2 apresenta os principais sistemas geradores de radioisótopos para medicina nuclear. 


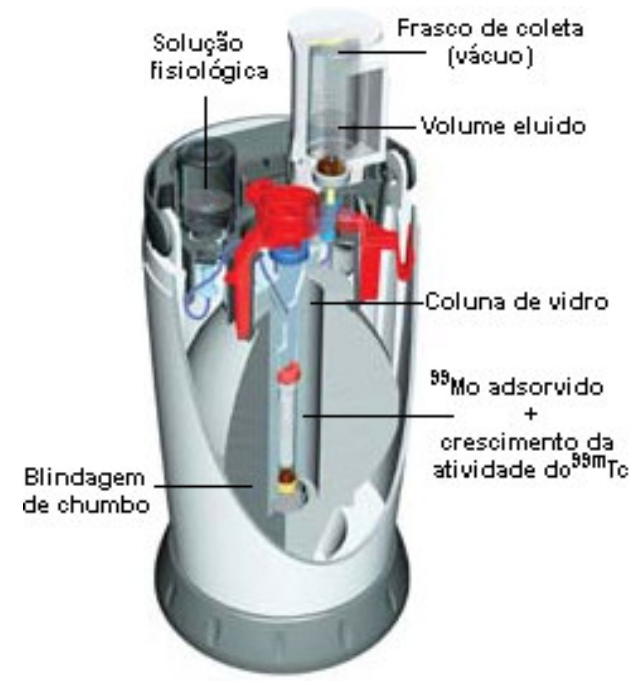

FIGURA 3 - Sistema gerador de ${ }^{99 m}$ Tc [20 ]

TABELA 2 - Geradores de radionuclídeos de SMN [19]

\begin{tabular}{|c|c|c|c|c|}
\hline \multirow{2}{*}{ Pai/filho } & \multicolumn{2}{|c|}{$T_{1 / 2}$ física } & \multirow{2}{*}{\multicolumn{2}{|c|}{$\begin{array}{l}\text { Energia do fóton } \\
\text { principal (keV) }\end{array}$}} \\
\hline & Pai (dias) & Filho (min) & & \\
\hline${ }^{195 m} \mathrm{Hg} /{ }^{195} \mathrm{Au}$ & 1,66 & 0,51 & & 262 \\
\hline${ }^{191} \mathrm{Os} /{ }^{191 \mathrm{~m}} \mathrm{Ir}$ & 15,4 & 0,08 & & 129 \\
\hline${ }^{188} \mathrm{~W} /{ }^{188} \mathrm{Re}$ & 69,4 & 1018,8 & & 155 \\
\hline${ }^{178} \mathrm{~W} /{ }^{178 m} \mathrm{~W}$ & 21,5 & 9,3 & & 93 \\
\hline${ }^{122} \mathrm{Xe} /{ }^{122} \mathrm{I}$ & 0,83 & 3,6 & 511, & 564 \\
\hline${ }^{118} \mathrm{Te} /{ }^{118} \mathrm{Sb}$ & 6 & 3,5 & 511 & 1230 \\
\hline${ }^{115} \mathrm{Cd} /{ }^{115 \mathrm{~m}} \mathrm{In}$ & 53,4 & 270 & & 336 \\
\hline${ }^{113} \mathrm{Sn} /{ }^{113 \mathrm{~m}} \mathrm{In}$ & 115,1 & 99,6 & & 392 \\
\hline${ }^{99} \mathrm{Mo} /{ }^{99 \mathrm{~m}} \mathrm{Tc}$ & 2,79 & 361,8 & & 140 \\
\hline${ }^{90} \mathrm{Sr} /{ }^{90} \mathrm{Y}$ & 10108 & 3852 & & 203 \\
\hline${ }^{82} \mathrm{Sr} /{ }^{82} \mathrm{Rb}$ & 25 & 1,26 & 511 & 780 \\
\hline${ }^{81} \mathrm{Rb} /{ }^{81 \mathrm{~m}} \mathrm{Kr}$ & 0,19 & 0,22 & & 191 \\
\hline${ }^{68} \mathrm{Ge} /{ }^{68} \mathrm{Ga}$ & 287 & 68,3 & 511 & 1080 \\
\hline${ }^{62} \mathrm{Zn} /{ }^{62} \mathrm{Cu}$ & 0,38 & 9,7 & 511 & 1173 \\
\hline${ }^{52} \mathrm{Fe} /{ }^{52 \mathrm{~m}} \mathrm{Mn}$ & 0,34 & 21 & 511 & 1424 \\
\hline
\end{tabular}




\subsection{Classificação dos Serviços de Medicina Nuclear}

Os serviços de medicina nuclear podem variar em tamanho e campo e aplicação, assim sendo apresentam especificidades e podem ser divididos e classificados da seguinte forma [21]:

- Classe 1: Instalação de serviço de medicina nuclear onde existe somente uma sala com gama câmara para a aquisição de imagem para diagnóstico, podendo estar conjugada a sala de exames.

- Classe 2: Instalação de serviços de medicina nuclear onde há várias salas com gama câmara para fins de aquisição de imagens para diagnóstico bem como locais destinados ao emprego de fármacos para terapia.

- Classe 3: Instalação de serviços de medicina nuclear que possuem vínculos acadêmicos (hospital escola) que além de prestar serviços da classe 2 ainda desenvolve pesquisas científicas relacionadas à medicina nuclear.

\subsection{Diagnóstico em Medicina Nuclear}

Atualmente as doenças que causam maior número de mortes no mundo são as doenças cardíacas e o câncer. De acordo com a Organização Mundial de Saúde as doenças cardíacas são responsáveis por 17 milhões de mortes por ano, quase um terço de todas as mortes no mundo. $O$ câncer causa 7 milhões de mortes por ano.

O diagnóstico precoce é vital para o tratamento eficiente de doenças. A natureza não-invasiva e a capacidade de diagnosticar doenças antes mesmo da sua manifestação física no organismo faz das técnicas de medicina nuclear uma ferramenta poderosa no combate a essas doenças.

Embora existam muitas técnicas de diagnóstico disponíveis, a medicina nuclear é uma das únicas que fornece informações fisiológicas do órgão de interesse. É esta habilidade que separa a medicina nuclear de outras modalidades de diagnóstico por imagem latente [22].

Atualmente, estão disponíveis, aproximadamente, 100 exames diferentes em medicina nuclear, que incluem estudos cardiovasculares, esquelético, pulmonar, hepatobiliar, gastrointestinal, neurológicos, geniturinários, endócrinos, oncológicos e de processos infecciosos e inflamatórios. Entre os exames mais comuns estão as cintilografias óssea, de coração, de tireóide, de baço, hepatobiliares, de inalação e perfusão pulmonar, de rins, e sistemas 
tomográficos; Tomografia Computadorizada por Emissão de Fóton Único (SPECT) e Tomografia Computadorizada por Emissão de Pósitron (PET).

\subsubsection{Cintilografia Óssea}

O principal benefício da cintilografia óssea é a alta sensibilidade em detectar vários tipos de doença de forma precoce e a capacidade de poder avaliar rapidamente todo o esqueleto a um baixo custo. De uma forma mais ampla, a captação dos traçadores ósseos representa a atividade osteoblástica e o fluxo regional do osso. Qualquer condição médica que altere um desses fatores, de forma positiva ou negativa, pode dar origem a uma cintilografia óssea anormal. $\mathrm{Na}$ maioria dos casos a significância dos achados cintilográficos é dada pelo contexto clínico. Sua principal indicação é na avaliação de metástases e tumores ósseos. O principal radionuclídeo empregado nessa prática é $0{ }^{99 \mathrm{~m}} \mathrm{Tc}$, com dose usual de 185 a $925 \mathrm{MBq}(15$ a $20 \mathrm{mCi})$ [19].

\subsubsection{Estudos cardiovasculares}

Existem vários procedimentos cintilográficos para diagnóstico e acompanhamento evolutivo das doenças cardíacas, os quais constituem cerca de $40 \%$ do total de exames realizados em SMN. O valor dos estudos cintilográficos reside principalmente no fato de não serem invasivos e de apresentarem uma boa exatidão na avaliação de vários parâmetros funcionais e metabólicos [23].

As técnicas que empregam radionuclídeos para estudo cardiovascular podem ser divididas basicamente em imagem de perfusão miocárdica, diagnóstico de infarto agudo do miocárdio, PET cardíaco, e imagem do infarto compactante. Essas técnicas servem para avaliar diversas patologias como doença arterial coronariana, infarto do miocárdio e miocardite.

Os principais radionuclídeos usados nessas técnicas, exceto o PET cardíaco são o ${ }^{201} \mathrm{TI}$ e o ${ }^{99 \mathrm{~m}} \mathrm{Tc}$. No caso do PET cardíaco os radionuclídeos mais importantes são ${ }^{82} \mathrm{Rb},{ }^{13} \mathrm{~N},{ }^{18} \mathrm{~F}$ e o ${ }^{11} \mathrm{C}[19]$.

\subsubsection{Cintilografia de tireóide}

O estudo do sistema endócrino foi um dos primeiros procedimentos em medicina nuclear. Quando o ${ }^{131}$ I foi posto à disposição da comunidade médica nos Estados Unidos, após a Segunda Guerra Mundial, pela Comissão de Energia 
Atômica, os especialistas logo perceberam que a percentagem de captação num determinado ponto, após a administração de ${ }^{131} \mathrm{I}$, era medida da função tireoidiana. Esta medida preliminar foi aprimorada com a intervenção medicamentosa para supressão e estímulo, com o objetivo de determinar, respectivamente, a autonomia ou reserva funcional da tireóide.

A cintilografia de tireóide e os estudos de captação permanecem como uma parte muito importante da prática da medicina nuclear, embora não sejam tão usados hoje como o foram no passado. A cintilografia de tiróide permanece a única técnica capaz de determinar o estado funcional dos nódulos, detecta metástases de carcinoma diferenciado de tireóide como tecido de origem de algumas massas de mediastino.

Os principais radionuclídeos usados para imagem da glândula tireóide incluem o ${ }^{131} \mathrm{I}$, o ${ }^{123} \mathrm{I}$ e o ${ }^{99 \mathrm{~m}} \mathrm{Tc}$ respectivamente [19].

\subsubsection{Cintilografia baço}

O baço serve como reservatório dos elementos sanguíneos, como local de seqüestro para microorganismos e partículas, como local em potencial para hematopoiese durante a falência da medula óssea, bem como fonte de resposta celular ou humoral a antígenos estranhos. Tem um papel na produção de leucócitos, contribui no processamento de plaquetas e tem função imunológica. $O$ baço pode ser visibilizado com vários radiotraçadores por mecanismos diferentes de captação, tais como ${ }^{99 m}$ Tc-enxofre-coloidal (função do retículo endotelial) ${ }^{111}$ Ileucócitos (migração de leucócitos), ${ }^{99 m}$ Tc-hemácias (distribuição de hemácias) e hemácias marcadas danificadas (seqüestro).

A cintilografia esplênica é na maioria das vezes indicada para pesquisar infarto, remanescente em pós-operatório, pesquisa de baço acessório ou esplenose [19].

\subsubsection{Cintilografia hepatobiliar}

Hoje a cintilografia hepatobiliar tem um campo bastante restrito, devido aos métodos alternativos de imagem abdominal, como a ressonância magnética, a tomografia computadorizada e a ultra-sonografia. Entretanto, os estudos hepáticos com radionuclídeos evoluíram e continuam dando informações funcionais e fisiopatológicas únicas, não disponíveis nos métodos de imagem 
anatômicos. As principais indicações para cintilografias hepatobiliares são para o diagnóstico de hemangiomas hepáticos, tumores hepáticos benignos e malignos, colecistite aguda, patologias obstrutivas das vias biliares, etc.

Os principais radionuclídeos usados em cintilografias hepatobiliares são ${ }^{99 \mathrm{~m}} \mathrm{Tc},{ }^{133} \mathrm{Xe},{ }^{67} \mathrm{Ga},{ }^{18} \mathrm{~F}[19]$.

\subsubsection{Cintilografia de ventilação e perfusão pulmonar}

A principal indicação de cintilografia de ventilação/perfusão pulmonar é a suspeita de embolia pulmonar. Esta é uma condição freqüentemente fatal e de difícil análise médica, e que muitas vezes só é diagnosticada após a morte do paciente. As informações de outros métodos diagnóstico junto à cintilografia de ventilação/perfusão ajudam no diagnóstico de embolia pulmonar. A técnica também é indicada em casos de doenças obstrutivas crônicas.

São duas classes de radiofármacos usados para estudos de ventilação: os gases radioativos e os aerossóis. Os gases radioativos incluem o ${ }^{133} \mathrm{Xe},{ }^{127} \mathrm{Xe}$ $\mathrm{e}^{81 \mathrm{~m}} \mathrm{Kr}$. Dentre estes, o mais usado é o ${ }^{133} \mathrm{Xe}$, cuja meia-vida é de 5,27 dias, o que facilita sua distribuição e seu armazenamento no laboratório de medicina nuclear. Está disponível comercialmente na forma de frasco com doses única e múltipla.

Comumente, uma dose de 370 a $740 \mathrm{MBq}(10$ a $20 \mathrm{mCi})$ é administrada por inalação para pacientes adultos.

Uma alternativa aos estudos de ventilação com gases radioativos são os radioaerossóis. Vários aerossóis foram testados para estudo de ventilação. O agente de escolha atual e o único aprovado pela autoridade regulamentar dos Estados Unidos da América FDA (Food and Drug Administration) é o aerossol de ${ }^{99 m}$ Tc-pentetato ( ${ }^{99 m}$ Tc-DTPA) [19].

\subsubsection{Cintilografia renal}

Os radionuclídeos têm sido usados para avaliar a função renal desde 1950. Os primeiros estudos usavam sonda externa e não produziam imagem, apenas histogramas atividade/tempo que evidenciavam o clareamento renal do radiotraçador.

Os estudos com a sonda foram substituídos por exames realizados em gama-câmaras acopladas a computador, que permitem a aquisição e o 
processamento de exames dinâmicos. Estes métodos mais modernos permitem estudos sofisticados do fluxo sanguíneo renal, da função renal, da anatomia e da integridade do sistema coletor. Vários radiofármacos diferentes foram utilizados para atender a esta categoria diagnóstica, entretanto o radiofármaco usado para obter imagem é o ${ }^{99 \mathrm{~m}}$ Tc-DTPA [19].

\subsubsection{Sistemas tomográficos}

A imagem radionuclídica convencional tem uma limitação que é a perda de contraste do orgão alvo, devido a radioatividade localizada nas estruturas vizinhas, que se superpõe àquela localizada no órgão alvo. O principal objetivo dos sistemas tomográficos de imagem é uma visão mais apurada da distribuição da radoatividade no paciente, com melhor definição dos detalhes da imagem. Técnicas tomográficas tem sido desenvolvidas para SPECT e PET.

A tomografia por emissão de fóton único é uma técnica tomográfica da medicina nuclear que faz uso de raios gama. É semelhante à técnica convencional de diagnóstico em medicina nuclear. A diferença está na forma de aquisição e tratamento da imagem adquirida. No SPECT a gama câmara adquire múltiplas imagens do paciente em 2 D a partir de vários ângulos. Após a aquisição dos dados as imagens são reconstruídas em um computador por meio de algoritmos, assim as imagens podem ser trabalhadas de forma tomográfica a partir de qualquer eixo, ou em reconstruções em 3D, semelhante às técnicas de CT, ressonância magnética nuclear e o PET.

As principais aplicações do SPECT são estudos funcionais cardíacos, certos tumores e estudo funcional do cérebro. Os principais radionuclídeos empregados nestas técnicas são ${ }^{123} \mathrm{I},{ }^{111} \mathrm{In},{ }^{201} \mathrm{TI} \mathrm{e}^{99 \mathrm{~m}} \mathrm{Tc}[14,19]$.

A tomografia por emissão de pósitron é um tipo de tomografia possível apenas por que ocorre a aniquilação dos pósitrons com subseqüente emissão de radiação gama. Quando os pósitrons se aniquilam por combinação com elétrons negativos, dão origem a dois fótons de 511 keV na mesma direção, porém com sentidos opostos $\left(180^{\circ}\right)$. Em contraste com a imagem do SPECT, que detecta eventos individualizados, a imagem PET requer dois detectores dispostos em lados opostos do objeto para por detectar os pares de fótons.

Os radionuclídeos usados no PET são necessariamente diferentes dos usados nos restantes exames da medicina nuclear, já que para esta última é 
importante a emissão de fótons gama, enquanto o PET se baseia no decaimento daqueles núcleos que emitem pósitrons. A TAB. 3 resume as características físicas dos principais radionuclídeos emissores de pósitrons

O PET é usado na análise de perfusão sanguínea e da atividade de diferentes regiões do cérebro, para detectar áreas isquêmicas e fibrosadas do coração, e em estudos oncológicos para distinguir massas benignas de malignas no pulmão, cólon, mama, linfomas e na detecção de metástases. Estudos oncológicos constituem $90 \%$ dos PET feitos atualmente [23].

TABELA 3 - Radionuclídeos emissores de pósitron usados em SMN [19]

\begin{tabular}{ccccl}
\hline Isótopo & $\begin{array}{c}\mathbf{T}_{\mathbf{1} / 2} \text { física } \\
\text { (min) }\end{array}$ & $\begin{array}{c}\text { Energia do } \\
\text { pósitron } \\
(\mathbf{M e V})\end{array}$ & $\begin{array}{c}\text { Penetração em } \\
\text { partes moles } \\
(\mathbf{m m})\end{array}$ & $\begin{array}{c}\text { Método de } \\
\text { produção }\end{array}$ \\
\hline${ }^{11} \mathrm{C}$ & 20 & 0,96 & 4,1 & Acelerador \\
${ }^{13} \mathrm{~N}$ & 10 & 1,19 & 5,4 & Acelerador \\
${ }^{15} \mathrm{O}$ & 2 & 1,73 & 7,3 & Acelerador \\
${ }^{18} \mathrm{~F}$ & 110 & 0,635 & 2,4 & Acelerador \\
${ }^{68} \mathrm{Ga}$ & 68 & 1,9 & 8,1 & Gerador $\left({ }^{68} \mathrm{Ge}\right)$ \\
${ }^{82} \mathrm{Rb}$ & 1,3 & 3,15 & 15,0 & Gerador $\left({ }^{82} \mathrm{Sr}\right)$ \\
\hline
\end{tabular}

Um avanço ainda maior na tecnologia destes equipamentos foi 0 advento dos PET/CTs. Estes sistemas constituídos por um PET unido a um tomógrafo helicoidal (CT) de atributo diagnóstico, permitindo a sobreposição (ou fusão) das imagens metabólicas do PET às imagens anatômicas do CT. São capazes de associar à alta sensibilidade metabólica e alta resolução espacial do PET uma correlação anatômica até então inconcebível, possibilitando a detecção precoce e a localização precisa de uma lesão. O PET/CT representa o estado da arte em tomografia por emissão de pósitrons [19].

O PET e principalmente o PET/CT vêm revolucionando grandes áreas da medicina moderna, particularmente a Oncologia, a Cardiologia e a Neurologia. Em Oncologia, tem sido usada para distinguir processos malignos de benignos, no estadiamento, detecção de recidiva, avaliação precoce e tardia da resposta à 
terapia, na determinação do prognóstico e da mudança de conduta clínica de pacientes com diversos tipos de tumores malignos. Em Neurologia, seu uso mais importante tem sido no diagnóstico diferencial das demências. Em Cardiologia, têm sido empregados principalmente na detecção do miocárdio hibernante [23].

Embora em termos mundiais o PET/CT ainda seja uma tecnologia bastante nova, já existem trabalhos importantes na literatura mostrando que a fusão das imagens PET/CT é superior às imagens do PET e às imagens do CT isoladas na detecção do tumor primário, de linfonodos acometidos e das metástases [24]. 


\section{REJEITOS RADIOATIVOS}

As aplicações nucleares que envolvem o uso de materiais radioativos, independente de sua finalidade, geram rejeitos radioativos em alguma etapa de seu manuseio. Os rejeitos radioativos gerados devem ser gerenciados de modo que possa garantir a proteção à saúde do homem e do meio ambiente, sem proporcionar encargos indevidos à geração futura.

Rejeito radioativo é definido pelo Organismo Internacional de Energia Atômica (OIEA) como "qualquer material que contenha ou esteja contaminado com radionuclídeos em concentrações ou valores de atividade maiores que os limites estabelecidos pela autoridade competente"[25].

Já a Comissão Nacional de Energia Nuclear (CNEN) define rejeito radioativo como sendo "qualquer material resultante de atividades humanas, que contenha radionuclídeos em quantidades superiores aos limites de isenção, especificadas na Norma CNEN-NE-6.02 Licenciamento de Instalações Radioativas, e para o qual a reutilização é imprópria ou não prevista" [26].

Os rejeitos radioativos podem ser classificados por diversos critérios: requisitos de segurança para seu manuseio; estágio de desenvolvimento da indústria nuclear em um país; regulamentos e normas de transporte; características físico-químicas; e, de acordo com a concentração de materiais radioativos presente nos rejeitos. São comumente utilizados nestas classificações os termos "nível baixo", "nível médio" e "nível alto", e embora os valores numéricos que diferenciam estes termos sejam distintos em diversos países, seguem os mesmos conceitos, que são:

- rejeitos de nível baixo - não requerem blindagem para manuseio e transporte;

- rejeitos de nível médio - requerem blindagem para manuseio e transporte e não são geradores de calor;

- rejeitos de nível alto - requerem blindagem para manuseio e transporte e também resfriamento, uma vez que são geradores de calor. 
$\mathrm{Na}$ prática, utiliza-se principalmente a classificação referente às características físicas e químicas e ao tipo de tratamento que o rejeito será submetido.

No Brasil a classificação em vigor baseia-se na forma física, na concentração de atividade e nos tipos de emissores presentes [27].

Os rejeitos radioativos podem ser ainda classificados de acordo com a sua origem, sendo divididos em três principais grupos: rejeitos do ciclo do combustível, rejeitos de descomissionamento e rejeitos institucionais.

Os rejeitos do ciclo do combustível são aqueles gerados durante a etapa do ciclo de fabricação e utilização do combustível nuclear, desde a mineração até o reprocessamento.

Descomissionamento significa o conjunto de práticas adotadas no final da vida útil de uma instalação, para inativá-la de forma segura. Estas práticas podem variar de um simples fechamento de uma instalação com remoção mínima de materiais radioativos, a uma completa remoção da instalação e por esse motivo as características dos rejeitos radioativos gerados variam muito.

Os rejeitos institucionais são aqueles gerados na produção e aplicação de radioisótopos na indústria, clínicas médicas, hospitais, centro de pesquisa, agricultura etc..

O setor nuclear dispensa atenção especial para a questão dos rejeitos radioativos, já que estes representam riscos potenciais para o homem devido à emissão de radiações que podem provocar lesões no organismo.

O conjunto de atividades, administrativas e técnicas, relacionadas ao manuseio dos rejeitos é chamado coletivamente de gerência de rejeitos radioativos e visam, por um lado, proteger as pessoas e ecossistema existente hoje e, por outro lado, legar à posteridade estes rejeitos em uma forma que não causem danos inaceitáveis e que não seja um problema que as futuras gerações tenham que resolver.

O setor nuclear sempre dispensou atenção especial aos rejeitos radioativos do ciclo do combustível, já que é a classe que gera maior volume de rejeitos bem como os de maior concentração de atividade quando comparado com as outras classes de rejeitos [28]. Entretanto, a crescente utilização de substâncias radioativas nas mais diversas áreas despertou também uma atenção 
especial para os rejeitos radioativos das aplicações nucleares. No Brasil a legislação específica para este tema é a Norma CNEN-NE-6.05 [7].

No capítulo cinco dessa Norma, apresenta-se uma série de requisitos para a operação de um sistema de gestão dos rejeitos radioativos em uma instalação radioativa, incluindo exigências para as edificações, os equipamentos e os materiais utilizados para a embalagem, transporte e armazenamento dos rejeitos e também exigências para aspectos administrativos do sistema, como registro e arquivo, treinamento e credenciamento de pessoal, autorização de descarte de rejeitos, entre outros [7].

Não há dúvidas que este documento é um marco relacionado à gestão dos rejeitos radioativos em instalações radioativas e ajuda em grande parte no papel de orientar no projeto de um sistema de gestão em instalações radioativas de usuários de isótopos. No entanto, por tratar de diferentes tipos de instalações acabou abordando de forma generalizada, não considerando aspectos particulares das diferentes instalações, como é o caso dos serviços de medicina nuclear.

A falta de um documento de referência que forneça orientações sobre como cumprir as exigências regulatórias de um sistema de gerência de rejeitos radioativos, em conformidade com a Norma CNEN-NE-6.05 [7], dificulta o projeto da instalação e a documentação do pedido de licença. Na maioria das vezes, na busca de soluções para a gestão dos rejeitos radioativos gerados nas instituições da área da saúde, recorre-se à literatura internacional, seja para questões mais genéricas [29, 30], seja para tópicos específicos como minimização da quantidade gerada [31, 32], caracterização e classificação de rejeitos [33], segurança física dos rejeitos [34], ou ainda no planejamento das instalações, dos custos e conformidade com leis e regulamentos [35]. 


\section{METODOLOGIA}

Para o desenvolvimento do presente trabalho, quatro atividades principais foram realizadas:

- Identificação e quantificação dos SMN: realizado por meio de consulta ao banco de dados do Sistema Integrado de Informações em Instalações Radioativas (SINRAD) da Comissão Nacional de Energia Nuclear (CNEN), onde se encontram discriminados nome, localização e data do vencimento de certificação de todos os SMS licenciados no país [15].

- Identificação e caracterização dos radioisótopos usados nos SMN: realizado por meio de consultas bibliográficas sobre os departamentos de radiofarmácia dos Institutos da CNEN [9, 10]. As informações que possibilitaram a identificação dos radioisótopos produzidos e importados, suas características físicas e químicas, os principais centros consumidores, bem como as perspectivas do setor no país foram avaliadas por meio da coleta de dados dos Institutos da CNEN [38].

- Levantamento bibliográfico sobre a gestão dos rejeitos radioativos em SMN: a consulta literária foi realizada buscando tanto aspectos técnicos da gestão, como aspectos regulamentares e normativos. As normas e regulamentos da CNEN foram as principais fontes da bibliografia nacional. A principal fonte de busca por bibliografias internacionais se deu junto ao acervo da International Nuclear Information System (INIS) [39], a base de dados do Organismo Internacional de Energia Atômica (OIEA) e o sistema de informações da Empresa Nacional de Resíduos Radioativos da Espanha (ENRESA) [40]. Dentre os títulos internacionais utilizados destacam-se as séries do OIEA.

- Visitas Técnicas a SMN de São Paulo: visita a cinco SMN da classe 2 localizados na cidade de São Paulo. Os serviços visitados apresentavam variações em relação ao tamanho, estrutura física, quantidade de exames realizados bem como na quantidade de rejeitos radioativos gerados. 
O objetivo geral das visitas foi desenvolver um estudo sobre a infraestrutura física e administrativa destinada à gestão dos rejeitos radioativo. Tal estudo visava identificar os problemas relacionados ao gerenciamento de rejeitos radioativos nos SMN e propor soluções com base nas normas da CNEN e nas recomendações d OIEA.

\subsection{SMN licenciados no Brasil}

As informações para a identificação e a quantificação dos SMN licenciados no país foram obtidas por meio de consultas ao banco de dados do Sistema Integrado de Informações em Instalações Radioativas (SINRAD) da CNEN. Neste banco, encontram-se discriminados o nome, a localização e a data do vencimento de certificação de todos os SMN licenciados, no entanto, essas informações estão dispostas de forma aleatória quanto a sua distribuição regional e os SMN classificados por ordem crescente de matrícula na CNEN [15].

As informações obtidas foram selecionadas e classificadas com o propósito de obter resultados que indicassem a distribuição dos SMN por regiões bem como a quantificação dos mesmos, tendo assim a dimensão do total de SMN que realizam a gestão de rejeitos radioativos.

Os resultados alcançados indicam que há no Brasil 282 Serviços de Medicina Nuclear (SMN), dos quais 164 estão localizados na região sudeste, 57 na região sul, 39 na região nordeste, 15 na região centro-oeste e 7 na região norte, como demonstrado na FIG. 4.

Com a segregação mais apurada das informações contidas no SINRAD foi possível compilar informações da localização e da quantidade dos SMN distribuídos no território nacional. Nas TAB. 4, 5, 6, 7 e 8 são apresentadas as distribuições dos SMN no Brasil. 


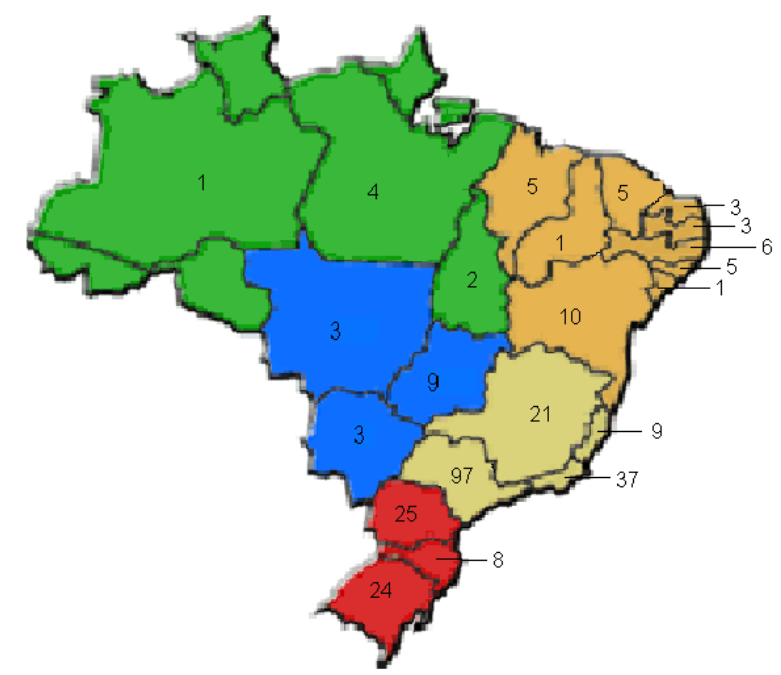

FIGURA 4 - Distribuição dos SMN em território nacional.

TABELA 4 - Localização dos SMN da Região Sudeste

\begin{tabular}{cccc}
\hline Estado & Município & $\begin{array}{c}\text { Número de } \\
\text { SMN }\end{array}$ & $\begin{array}{c}\text { Total no } \\
\text { Estado }\end{array}$ \\
\hline Espírito Santo & Vitória & 5 & \\
& Cachoeiro do Itapemirim & 1 & \\
& Colatina & 1 & 9 \\
Sinas Gerais & Vila Velha & 1 & \\
& Belo Horizonte & 1 & \\
& Barbacena & 10 & \\
& Governador Valadares & 1 & \\
& Ipatinga & 1 & \\
& Juiz de Fora & 2 & \\
& Montes Claros & 1 & \\
& Nova Lima & 1 & \\
& Ponte Nova & 1 & \\
& Uberaba & 1 & \\
& Varginha & 1 & \\
& Viçosa & 1 & \\
\hline
\end{tabular}


TABELA 4 - Localização dos SMN da Região Sudeste (cont.)

\begin{tabular}{|c|c|c|c|}
\hline Estado & Município & $\begin{array}{l}\text { Número } \\
\text { de SMN }\end{array}$ & $\begin{array}{l}\text { Total no } \\
\text { Estado }\end{array}$ \\
\hline \multirow[t]{11}{*}{ Rio de Janeiro } & Barra Mansa & 1 & \\
\hline & Campo dos Goytacazes & 1 & \\
\hline & Duque de Caxias & 1 & \\
\hline & Itaperuna & 1 & \\
\hline & Macaé & 2 & \\
\hline & Niterói & 3 & \\
\hline & Nova Friburgo & 1 & \\
\hline & Nova Iguaçu & 2 & \\
\hline & Petrópolis & 2 & \\
\hline & Rio de Janeiro & 22 & \\
\hline & Volta Redonda & 1 & \\
\hline \multirow[t]{27}{*}{ São Paulo } & Americana & 1 & \\
\hline & Araçatuba & 2 & \\
\hline & Araraquara & 1 & \\
\hline & Barretos & 1 & \\
\hline & Bauru & 2 & \\
\hline & Botucatu & 1 & \\
\hline & Campinas & 8 & \\
\hline & Catanduva & 1 & \\
\hline & Franca & 1 & \\
\hline & Jaú & 1 & \\
\hline & Jundiaí & 1 & \\
\hline & Limeira & 1 & \\
\hline & Marília & 1 & \\
\hline & Osasco & 1 & \\
\hline & Piracicaba & 1 & \\
\hline & Presidente Prudente & 1 & \\
\hline & Ribeirão Preto & 4 & \\
\hline & Santo André & 4 & \\
\hline & Santos & 1 & \\
\hline & São Bernardo do Campo & 3 & \\
\hline & São Carlos & 1 & \\
\hline & São José do Rio Preto & 8 & \\
\hline & São José dos Campos & 2 & \\
\hline & São Paulo & 44 & \\
\hline & Sorocaba & 3 & \\
\hline & Taubaté & 1 & \\
\hline & Votuporanga & 1 & 97 \\
\hline
\end{tabular}


TABELA 4 - Localização dos SMN da Região Sul

\begin{tabular}{cccc}
\hline Estado & Município & $\begin{array}{c}\text { Número } \\
\text { de SMN }\end{array}$ & $\begin{array}{c}\text { Total no } \\
\text { Estado }\end{array}$ \\
\hline Paraná & Campo Mourão & 1 & \\
& Cascavel & 3 & \\
Curitiba & 11 & \\
& Londrina & 6 & \\
& Maringá & 1 \\
& Ponta Grossa & 1 \\
Sano José dos Pinhais & 1 \\
& Umuarama & 1 \\
& Chapecó & 1 \\
& Criciúma & 1 \\
& Florianópolis & 2 \\
Itajaí & 1 \\
& Joinville & 2 \\
& São José & 1 \\
& Canoas & 1 \\
& Caxias do Sul & 1 \\
& Erechim & 1 \\
& Lajeado & 1 \\
& Novo Hamburgo & 1 \\
& Passo Fundo & 1 \\
& Pelotas & 2 \\
& Porto Alegre & 13 \\
& Rio Grande & 1 \\
Santa Maria & 2 \\
\hline
\end{tabular}

TABELA 6 - Localização dos SMN da Região Norte

\begin{tabular}{cccc}
\hline Estado & Município & $\begin{array}{c}\text { Número } \\
\text { de SMN }\end{array}$ & $\begin{array}{c}\text { Total no } \\
\text { Estado }\end{array}$ \\
\hline Amazonas & Manaus & 1 & 1 \\
Pará & Belém & 4 & 4 \\
Tocantins & Palmas & 2 & 2 \\
\hline
\end{tabular}


TABELA 7 - Localização dos SMN da Região Nordeste

\begin{tabular}{cccc}
\hline Estado & Município & $\begin{array}{c}\text { Número } \\
\text { de SMN }\end{array}$ & $\begin{array}{c}\text { Total no } \\
\text { Estado }\end{array}$ \\
\hline Alagoas & Maceió & 5 & \\
Bahia & Feira de Santana & 1 & \\
& Itabuna & 1 & \\
& Salvador & 7 & \\
Vitória da Conquista & 1 & \\
Maranhão & Imperatriz & 1 & \\
& São Luis & 4 & \\
Ceará & Barbalha & 1 & \\
& Fortaleza & 4 & \\
Paraíba & Campina Grande & 1 & \\
& João Pessoa & 2 & \\
Pernambuco & Caruaru & 1 & \\
& Recife & 5 & \\
Piauí & Teresina & 1 & \\
Rio Grande do Norte & Natal & 3 & \\
Sergipe & Aracaju & 1 & 39 \\
\hline
\end{tabular}

TABELA 8 - Localização dos SMN da Região Centro-Oeste

\begin{tabular}{|c|c|c|c|}
\hline Estado & Município & $\begin{array}{l}\text { Número } \\
\text { de SMN }\end{array}$ & $\begin{array}{c}\text { Total no } \\
\text { Estado }\end{array}$ \\
\hline \multirow[t]{2}{*}{ Distrito Federal } & Brasília & 5 & \\
\hline & Taguatinga & 1 & 6 \\
\hline \multirow[t]{2}{*}{ Goiás } & Anápolis & 1 & \\
\hline & Goiânia & 2 & 3 \\
\hline \multirow[t]{2}{*}{ Mato Grosso do Sul } & Campo Grande & 2 & \\
\hline & Dourados & 1 & 3 \\
\hline Mato Grosso & Cuiabá & 3 & 3 \\
\hline
\end{tabular}




\subsection{Radioisótopos usados em SMN}

O uso de radioisótopos para fins diagnósticos e terapêuticos se dá por meio de uma grande quantidade de radionuclídeos que podem ser administrados ao paciente por via oral, endovenosa e por inalação. A atividade dos radionuclídeos empregados e sua forma física dependem de sua aplicação, e influenciam diretamente nas características dos rejeitos radioativos gerados. As TAB. 9 e 10 apresentam um resumo das características físicas dos principais radionuclídeos utilizados para terapia e diagnóstico em medicina nuclear.

TABELA 9 - Radionuclídeos utilizados em terapia [36, 37]

\begin{tabular}{|c|c|c|c|c|}
\hline Isótopo & $\mathrm{T} 1 / 2$ & Principal aplicação & $\begin{array}{l}\text { Atividade típica } \\
\text { por aplicação }\end{array}$ & $\begin{array}{l}\text { Rejeitos } \\
\text { gerados }\end{array}$ \\
\hline${ }^{32} \mathrm{P}$ & $14,3 d$ & $\begin{array}{l}\text { Tumores hepáticos, } \\
\text { metástases ósseas }\end{array}$ & Até $200 \mathrm{MBq}$ & Sólido, líquido \\
\hline${ }^{67} \mathrm{Cu}$ & $2,6 \mathrm{~d}$ & Tumores diversos & Até1 GBq & Sólido, líquido \\
\hline${ }^{80 \mathrm{~m}} \mathrm{Br}$ & $4,42 \mathrm{~h}$ & Carcinoma de mama & -- & -- \\
\hline${ }^{89} \mathrm{Sr}$ & $50,5 d$ & $\begin{array}{l}\text { Tratamento paliativo da dor } \\
\text { causado pela metástase óssea. }\end{array}$ & Até 300 MBq & Sólido, líquido \\
\hline${ }^{90} \mathrm{Y}$ & $2,7 \mathrm{~d}$ & Atrites, reumatismo, etc. & Até $300 \mathrm{MBq}$ & Sólido, líquido \\
\hline${ }^{131}$ & $8,0 \mathrm{~d}$ & $\begin{array}{l}\text { Tratamento de hipertireoidismo } \\
\text { e câncer }\end{array}$ & Até11 GBq & $\begin{array}{l}\text { Sólido, líquido, } \\
\text { excretas }\end{array}$ \\
\hline 125 & $60 d$ & $\begin{array}{l}\text { Tumores neuroendócrinos, } \\
\text { carcinoma de mama }\end{array}$ & -- & -- \\
\hline${ }^{153} \mathrm{Sm}$ & $47 \mathrm{~h}$ & $\begin{array}{l}\text { Tratamento paliativo da dor } \\
\text { causado pela metástase óssea. }\end{array}$ & Até $8 \mathrm{GBq}$ & Sólido, líquido \\
\hline${ }^{169} \mathrm{Er}$ & $9,3 \mathrm{~d}$ & Sinovectomia & Até $500 \mathrm{MBq}$ & Sólido, líquido \\
\hline${ }^{186} \mathrm{Re}$ & $3,8 \mathrm{~d}$ & $\begin{array}{l}\text { Sinovectomia, carcinoma } \\
\text { medular de tireóide }\end{array}$ & Até $500 \mathrm{MBq}$ & Sólido líquido \\
\hline${ }^{188} \mathrm{Re}$ & $17 \mathrm{~h}$ & Radionuclídeo potencial ${ }^{1}$ & Até $500 \mathrm{MBq}$ & Sólido, líquido \\
\hline${ }^{198} \mathrm{Au}$ & $2,7 d$ & Sinovectomia, terapia intratecal & -- & -- \\
\hline
\end{tabular}

(1) Uma série de compostos está sendo investigada para a marcação com ${ }^{188} \mathrm{Re}$, cujo objetivo principal é identificar os compostos que apresentem características farmacocinéticas para o uso terapêutico. 
TABELA 10 - Radionuclídeos utilizados em diagnóstico [36, 37]

\begin{tabular}{|c|c|c|c|c|}
\hline Isótopo & $\mathrm{T} 1 / 2$ & Principal aplicação & $\begin{array}{l}\text { Atividade } \\
\text { típica por } \\
\text { aplicação }\end{array}$ & $\begin{array}{l}\text { Rejeitos } \\
\text { gerados }\end{array}$ \\
\hline${ }^{13} \mathrm{~N}$ & $10 \mathrm{~m}$ & PET & Até $2 \mathrm{GBq}$ & Sólido, líquido \\
\hline${ }^{11} \mathrm{C}$ & $20,4 \mathrm{~m}$ & PET & Até $2 \mathrm{GBq}$ & Sólido, líquido \\
\hline${ }^{15} \mathrm{O}$ & $122 \mathrm{~s}$ & PET & Até $500 \mathrm{MBq}$ & Sólido, líquido \\
\hline${ }^{18} \mathrm{~F}$ & $1,8 \mathrm{~h}$ & PET & Até $500 \mathrm{MBq}$ & Sólido, líquido \\
\hline${ }^{38} \mathrm{~K}$ & $7,6 \mathrm{~m}$ & PET & Até $1 \mathrm{GBq}$ & Sólido, líquido \\
\hline${ }^{45} \mathrm{Ca}$ & $4,54 d$ & Diagnóstico médico & Até100 MBq & Sólido, líquido \\
\hline${ }^{67} \mathrm{Ga}$ & $3,3 d$ & Estudo de tumores hepáticos & Até $200 \mathrm{GBq}$ & Sólido, líquido \\
\hline${ }^{68} \mathrm{Ga}$ & $68,2 \mathrm{~m}$ & PET & Até $2 \mathrm{GBq}$ & Sólido, líquido \\
\hline${ }^{75} \mathrm{Br}$ & $98 \mathrm{~m}$ & Diagnóstico médico & - & Sólido, líquido \\
\hline${ }^{76} \mathrm{Br}$ & $16,2 \mathrm{~h}$ & Diagnóstico médico & & Sólido, líquido \\
\hline${ }^{81} \mathrm{~m}_{\mathrm{Kr}}$ & $13,3 \mathrm{~s}$ & $\begin{array}{l}\text { Estudo de ventilação } \\
\text { pulmonar }\end{array}$ & Até $6 \mathrm{GBq}$ & Gasoso, líquido \\
\hline${ }^{82} \mathrm{Rb}$ & $76 \mathrm{~s}$ & PET & - & Sólido, líquido \\
\hline${ }^{85} \mathrm{Sr}$ & $64,8 d$ & Diagnóstico médico & Até $50 \mathrm{MBq}$ & Sólido, líquido \\
\hline${ }^{99 \mathrm{~m}} \mathrm{Tc}$ & $6,0 \mathrm{~h}$ & Diagnóstico médico & Até $100 \mathrm{GBq}$ & Sólido, líquido \\
\hline${ }^{123} \mid$ & $13,2 \mathrm{~h}$ & Diagnóstico médico & Até $500 \mathrm{MBq}$ & Sólido, líquido \\
\hline${ }^{127} \mathrm{Xe}$ & $36,4 d$ & $\begin{array}{l}\text { Estudo de ventilação } \\
\text { pulmonar }\end{array}$ & Até $200 \mathrm{MBq}$ & Gasoso, sólido \\
\hline${ }^{133} \mathrm{Xe}$ & & $\begin{array}{l}\text { Estudo de tumores hepáticos } \\
\text { e de ventilação pulmonar }\end{array}$ & - & - \\
\hline${ }^{137} \mathrm{Xe}$ & 5,27 & $\begin{array}{l}\text { Estudo de ventilação } \\
\text { pulmonar }\end{array}$ & Até $740 \mathrm{MBq}$ & Gasoso, sólido \\
\hline
\end{tabular}

4.3 Visitas aos SMN do Município de São Paulo

Durante o período de fevereiro à agosto de 2007 foram realizadas visitas a cinco $S M N$, dois públicos e três privados, denominados neste trabalho de SMN A, SMN B, SMN C, SMN D e SMN E. Todas as visitas tiveram duração aproximada de um mês, (quatro horas diárias de segunda à sexta-feira). Todas as 
visitas foram autorizadas e supervisionadas pelos responsáveis em radioproteção dos respectivos serviços.

Todos os SMN visitados têm autorização de funcionamento expedida pela CNEN, sendo o plano de gerência de rejeitos radioativos um dos requisitos para a autorização.

A TAB. 11 apresenta o período em que os SMN foram visitados bem como o número de exames realizados mensalmente.

TABELA 11 - SMN do Município de São Paulo visitados

\begin{tabular}{cccc}
\hline SMN & $\begin{array}{c}\text { Período das } \\
\text { visitas }\end{array}$ & Aplicação & $\begin{array}{c}\mathbf{N}^{\circ} \text { de exames } \\
\text { realizados (mês) }\end{array}$ \\
\hline A & Fev - Mar & Diagnóstico/terapia & 489 \\
B & Abr - Mai & Diagnóstico/terapia & 2125 \\
C & Mai - Jul & Diagnóstico & 625 \\
D & Jul - Ago & Diagnóstico & 300 \\
E & Ago & Diagnóstico/terapia & 800 \\
\hline
\end{tabular}

Os rejeitos radioativos resultantes do uso de fontes de radiação nesses SMN contêm radionuclídeos emissores $\beta$-puro ou $\beta$ - $\gamma$ de meia-vida curta e baixo nível de radiação, e representam pouco risco quando manuseados adequadamente. Basicamente, três fluxos de rejeitos são gerados: excreta, sólidos e perfuro-cortantes.

A excreta dos pacientes submetidos a procedimentos de Medicina Nuclear é liberada diretamente na rede de esgoto sanitário.

Os rejeitos sólidos são constituídos em sua maioria por material de higiene e limpeza (papel absorvente, algodão, tecidos), material de forração (cobertura de leitos e travesseiros), objetos de uso pessoal (talheres, pratos, escovas) e material de segurança (luvas, sapatilhas).

As seringas, agulhas e os pequenos frascos onde os radioisótopos foram transportados e manipulados constituem os perfuro-cortantes.

Os rejeitos sólidos são coletados em sacos plásticos exclusivos para rejeitos radioativos e posteriormente armazenados para futura gestão. Os perfuro- 
cortantes são coletados em caixas de papelão especiais e também são armazenados para futura gestão.

A maioria dos rejeitos radioativos de SMN apresenta características que possibilitam a sua liberação imediata do controle regulatório ou, após um período de decaimento, dentro de condições e limites estabelecidos pela CNEN.

O objetivo geral das visitas foi avaliar a infra-estrutura física e administrativa destinada à gestão desses rejeitos radioativos, tais como localização, material utilizado para revestimento de piso e paredes, e segurança física. Estes e outros aspectos relevantes da gestão de rejeitos em SMN serão apresentados e discutidos a seguir. 


\section{RESULTADOS E DISCUSSÕES}

Todos os aspectos relacionados à gestão de rejeitos radioativos que foram avaliados durante a execução deste trabalho serão discutidos a seguir. Para cada tópico, serão apresentadas, primeiramente, as recomendações e informações indicadas nas referências bibliográficas consultadas, posteriormente serão apresentadas as situações encontradas durante as visitas e, finalmente, serão apresentadas as sugestões propostas.

\subsection{Localização do depósito}

A Norma 6.05, em seu capítulo cinco, estabelece critérios sobre a definição do local para o armazenamento provisório de rejeitos, dentre os quais: "... situar-se distante das áreas normais de trabalho..." [7]. Recomendações internacionais não especificam uma localização para o armazenamento provisório de rejeitos. Recomendam apenas que o depósito deve estar localizado fora das rotas disponíveis ao público e de acesso fácil para o transporte ou descarte do rejeito [42].

Nas visitas observou-se que todos os SMN visitados dispunham de um local exclusivo destinado ao armazenamento provisório de rejeitos, porém com localização muito variada. As figuras a seguir (FIG. 5, 6, 7, 8 e 9) apresentam ilustrações que representam os SMN visitados, evidenciando apenas os locais de maior geração de rejeitos e localização do depósito de rejeitos. A FIG. 5 apresenta um esquema do SMN A.

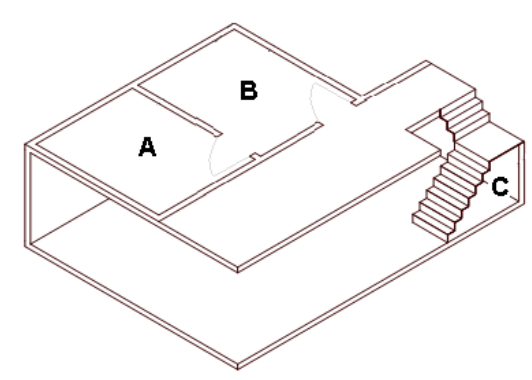

A - Lab. de manipulação de radioisótopos;

B - Sala de administração dos radioisótopos;

C - Depósito de rejeitos radioativos.

FIGURA 5 - Serviço de medicina nuclear $A$ 
O SMN B foi o maior serviço visitado. Ele faz parte de um grande complexo hospitalar com várias especialidades médicas e é separado fisicamente em três partes dentro de dois edifícios, como é representado na FIG. 6.

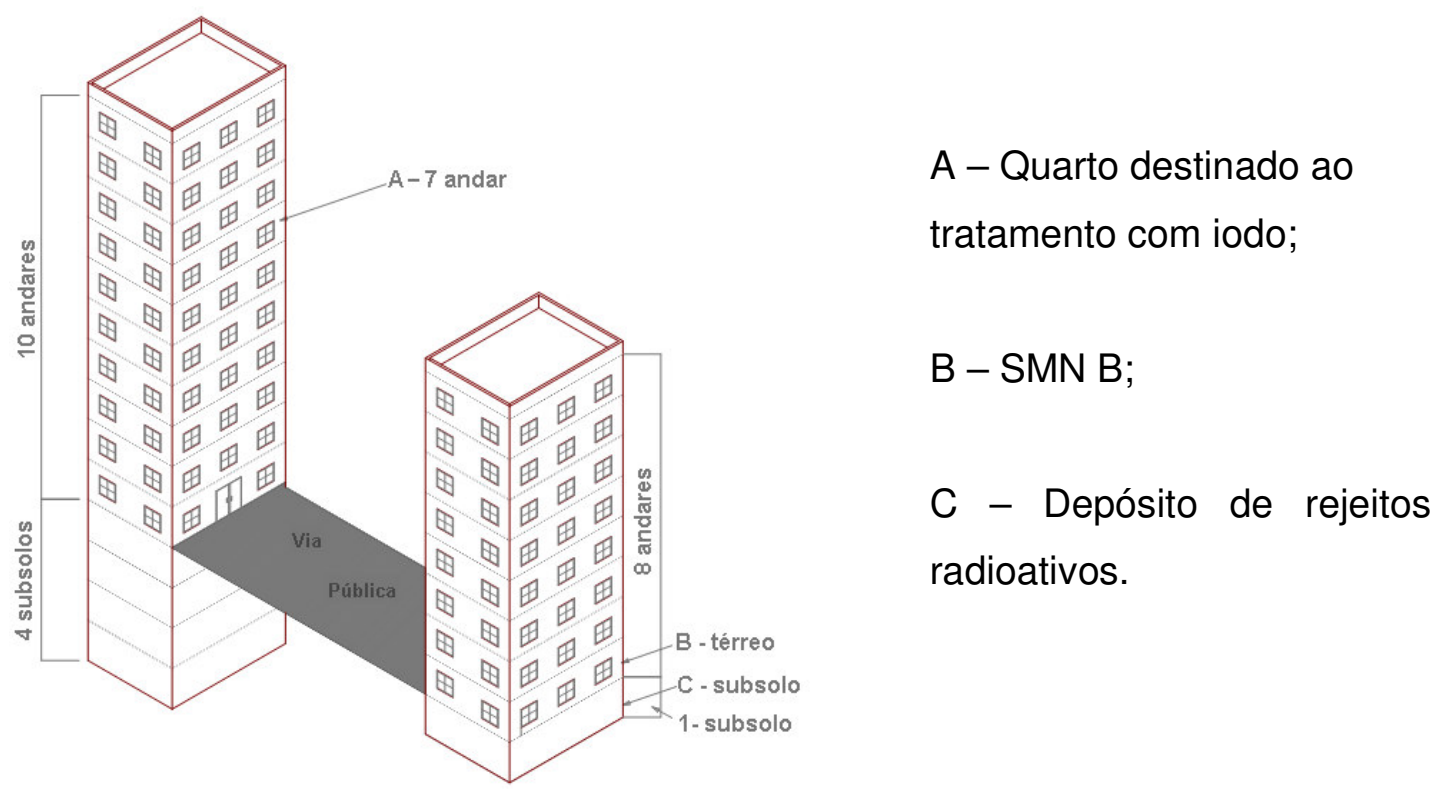

FIGURA 6 - Serviço de medicina nuclear B

O SMN C é uma edificação constituída de dois pavimentos; um andar superior destinado a administração e um andar térreo dedicado as aplicações técnicas do SMN. Na FIG. 7 apresenta-se a localização do SMN C.

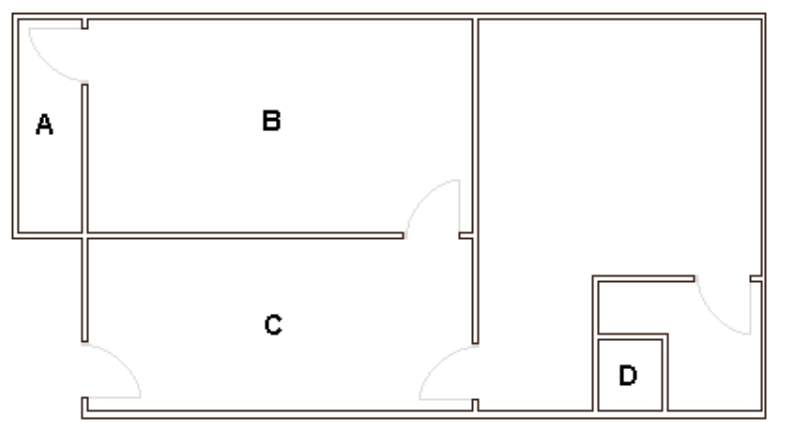

A - Depósito de rejeitos radioativos; B - Lab. de manipulação de radioisótopos;

C - Sala de administração dos radioisótopos;

D - Depósito de rejeitos radioativos (caixa de concreto com tampa).

FIGURA 7 - Serviço de medicina nuclear C 
O depósito de rejeitos do SMN D é conjugado com o laboratório de manipulação de radioisótopos, como apresentado na FIG. 8.

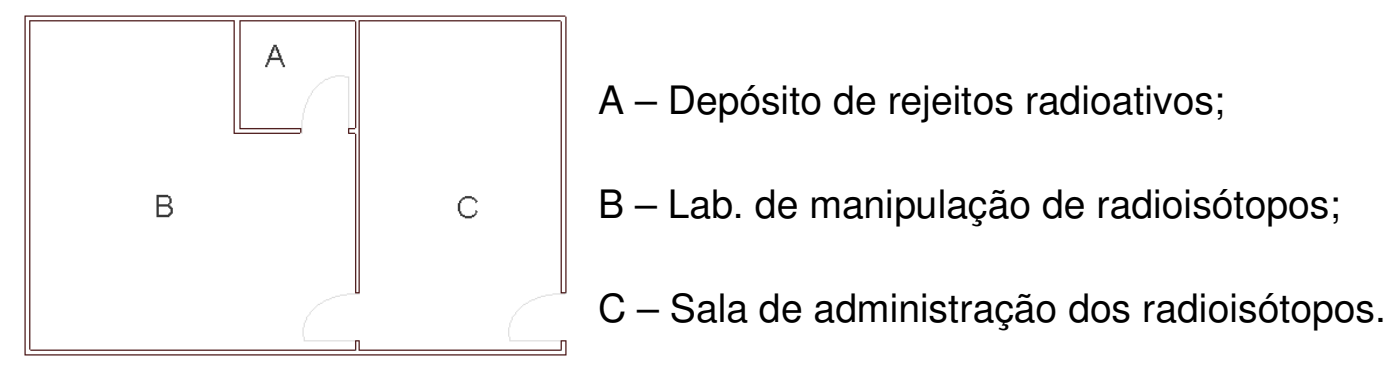

FIGURA 8 - Serviço de medicina nuclear D

O depósito de rejeitos do SMN E é conjugado com o laboratório de manipulação de radioisótopos, como apresentado na FIG.9.

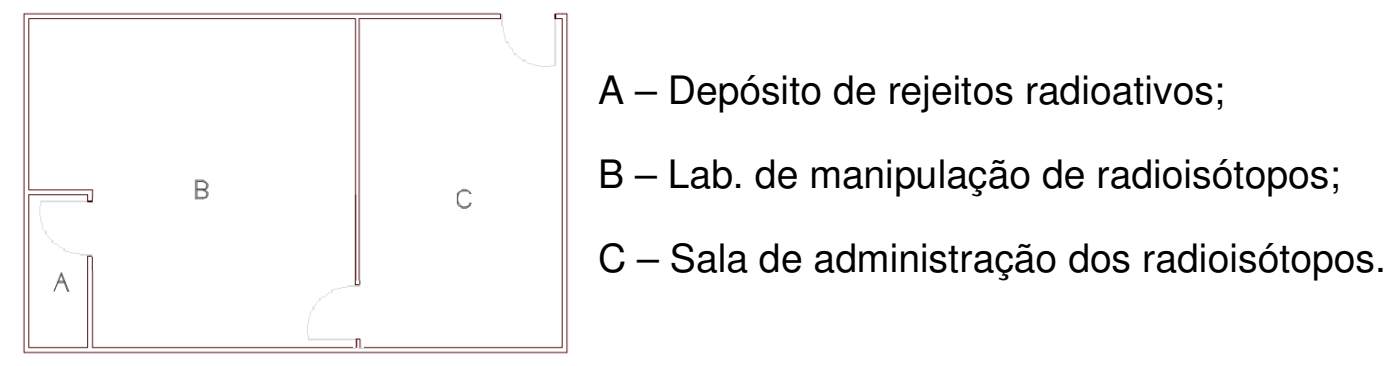

FIGURA 9 - Serviço de medicina nuclear E

As distâncias entre os laboratórios de manipulação de radioisótopos e os depósitos de rejeitos radioativos dos SMN estão apresentadas na TAB. 12.

Todos os SMN visitados dispunham de um local exclusivo para o armazenamento provisório de rejeitos, entretanto tais depósitos são adaptações de locais destinados a outro propósito.

Os SMN devem possuir depósito de rejeitos radioativos, cuja localização depende do volume de rejeitos gerado, podendo ser o próprio laboratório ou até uma sala exclusiva, preparada e dedicada ao armazenamento de rejeitos. Em qualquer caso o local deve ser o mais próximo da sala de manipulação de radioisótopos, se possível tendo interligação entre eles para que o percurso de transporte do rejeito seja reduzido, restringindo assim o perímetro de possíveis acidentes. 
TABELA 12 - Locais de armazenamento de rejeitos radioativos

\begin{tabular}{|c|c|c|}
\hline SMN & $\begin{array}{l}\text { Distância entre o depósito de rejeitos e o } \\
\text { laboratório de manipulação de isótopos }\end{array}$ & $\begin{array}{c}\text { Via de acesso } \\
\text { laboratório/Depósito }\end{array}$ \\
\hline A & $20 \mathrm{~m}$ (subsolo do SMN) & Escadas \\
\hline $\mathrm{B}^{(1)}$ & $200 \mathrm{~m}$ (localizado fora do SMN) & $\begin{array}{l}\text { Corredores e } \\
\text { elevadores }\end{array}$ \\
\hline C & 20 m e o outro conjugado ao laboratório & Por uma sala \\
\hline D & Conjugado ao laboratório & (2) \\
\hline$E$ & Conjugado ao laboratório & (2) \\
\hline
\end{tabular}

5.2 Transporte interno de rejeitos radioativos

O transporte do rejeito radioativo é requerido, sempre que for remover o rejeito radioativo do local onde ele é produzido até o local onde será armazenado. Em casos de volumes consideráveis de rejeitos será empregado veículo para o transporte interno dos mesmos.

Quanto ao transporte realizado no interior de instalações, a legislação nacional determina que este deve "ser supervisionado e efetuado de acordo com procedimentos elaborados pelo supervisor de radioproteção da instalação" [43].

Uma das recomendações internacionais que trata do transporte interno dos rejeitos radioativos é bem específica no que diz respeito às características do veículo e também ao planejamento de rota de transporte de rejeitos [42].

Entre os SMN visitados, apenas um (SMN B) faz uso de veículo para o transporte interno dos rejeitos. O uso do veículo pelo SMN B se justifica pela distância entre os locais onde os rejeitos são produzidos até o local onde são armazenados. Outro fator que justifica o emprego de um veículo é a quantidade de rejeitos gerados por esse serviço. $\mathrm{Na}$ TAB. 13, são apresentadas as quantidades de rejeitos radioativos gerados pelos $S M N$ visitados. 
TABELA 13 - Quantidade de rejeitos gerados pelos SMN visitados

\begin{tabular}{ccc}
\hline SMN & $\begin{array}{c}\text { Volume mensal } \\
(\mathbf{L})\end{array}$ & $\begin{array}{c}\text { Massa mensal } \\
(\mathbf{k g})\end{array}$ \\
\hline A & $(*)$ & 145 \\
B & 13025 & 1302 \\
C & 450 & 85 \\
D & 330 & 65 \\
E & 4350 & 475 \\
\hline$(*)$ não informado & &
\end{tabular}

O veículo empregado no SMN B é um carro de mão, muito semelhante a um veículo utilizado no transporte de roupa hospitalar, constituído de material plástico, com quatro rodas e com a cor predominante branca, fechado, em forma de cesto, sem tampa, com capacidade interna de 660 litros. Não possui divisórias internas e nem sinalização externa.

O modo de transporte e o itinerário devem ser planejados, de forma que o número de viagens e o tempo no qual a carga fique em trânsito sejam reduzidos ao mínimo. É recomendado ainda que esse procedimento seja feito em horários de menor movimento e não coincidentes com a distribuição de roupas, alimentos e medicamentos, períodos de visita e, se possível, no final do expediente de trabalho.

Antes da acomodação dos embalados de rejeitos no veículo deve-se observar se estes estão intactos e sejam capazes de suportar as condições de transporte sem extravasar seu conteúdo.

O veículo utilizado no transporte de rejeitos deve possuir as seguintes características:

- ser de fácil manuseio, levando-se em consideração a massa, o volume e a geometria do mesmo;

- ter sua superfície externa livre de saliências, com bordas e cantos arredondados, de forma a poder ser facilmente descontaminado;

- ser constituído de material rígido, lavável e impermeável;

- ser provido de tampa;

- ser provido de rodas revestidas de material que reduza trepidações;

- possuir o símbolo internacional de presença de radiação ionizante (trifólio de cor preta ou magenta) em rótulos de fundo amarelo e contornos pretos, 
acrescido da expressão "REJEITO RADIOATIVO", em local de fácil visualização;

- possuir tamanho que comporte os rejeitos gerados diariamente pela instalação de forma que diminua o máximo possível o número de viagens;

- não ser utilizado para armazenamento ou transporte de outras mercadorias;

- suportar possíveis choques mecânicos;

- ter capacidade de reter fluidos em seu interior e não possuir válvula de drenagem no fundo;

- ser manipulado, exclusivamente, por funcionários autorizados, treinados e informados sobre os riscos radiológicos associados ao transporte [ 42 ];

- ter fixados em sua tampa as rotas e os horários de transporte.

\subsection{Sinalização e fixação de procedimentos}

A CNEN determina que o local destinado a deposição inicial de rejeitos seja classificado como área restrita, devendo ser identificado com o símbolo internacional de radiação em sua porta [17]. Essa recomendação é encontrada também em todas as referências internacionais que tratam do tema.

A norma da CNEN que trata especificamente da gestão dos rejeitos radioativos [7] determina ainda que o local destinado ao armazenamento provisório de rejeitos tenha todos os procedimentos pertinentes fixados em paredes, quadros e outros lugares bem visíveis, entretanto não dispõe de forma específica sobre como devem ser elaborados esses procedimentos.

Referências internacionais não mencionam a fixação de procedimentos pertinentes a gestão de rejeitos radioativos próximo ao depósito de rejeitos. No entanto, recomendam sua adoção em outros locais, como é o caso de instruções fixadas nos banheiros exclusivos aos pacientes. [44]

Todos os SMN visitados tinham seu depósito devidamente identificado de forma coerente com as determinações da CNEN. O que se observou nesses serviços foi a falta de padronização dos procedimentos e os diferentes locais escolhidos para a fixação dos mesmos.

A adoção de procedimentos padronizados deve ser feita em duas situações, normais e acidentais. São consideradas situações normais, as 
situações em que a fonte radiativa está controlada e a exposição pode ser limitada com o emprego de medidas adequadas de controle. Situações acidentais são aquelas em que se perde o controle sobre a fonte de radiação e a exposição, portanto, deve ser limitada unicamente com medidas corretivas.

Para que se adotem procedimentos para situações normais e ou acidentais faz-se necessário conhecer a rotina da instalação, os rejeitos radioativos que são gerados, o tratamento dado a eles, bem como prever os possíveis acidentes. Assim sendo é possível planejar e estabelecer condutas padrão em situações normais e acidentais.

O local do depósito para a fixação de procedimentos para as duas situações deve ser a parte interna e externa da porta do depósito.

Deve estar fixado do lado externo da porta do depósito, além do símbolo internacional de radiação ionizante, os números de telefone do serviço de radioproteção da unidade, do plantão de emergência do instituto da CNEN mais próximo, do corpo de bombeiros e da polícia e os seguintes avisos:

- Área restrita;

- Proibida a entrada de pessoas não autorizadas;

A parte interna da porta do depósito deve estar sinalizada com os seguintes avisos:

- Permanecer dentro do depósito apenas o tempo necessário para a realização dos procedimentos;

- Manter-se a maior distância possível dos rejeitos ao manuseá-los;

- Posicionar o rejeito de forma que a etiqueta de identificação seja de fácil visualização;

- Cuidar para não misturar os rejeitos radioativos com características diferentes.

Os procedimentos também podem ser fixados em locais onde há maior manipulação de radioisótopos, e outros locais onde ainda exista risco de contaminação. 
5.4 Segurança física do depósito de rejeitos radioativos

A legislação nacional menciona que o depósito de rejeitos deve "conter com segurança os rejeitos radioativos, do ponto de vista físico e radiológico, até que possam ser removidos para local determinado pela CNEN" [7]. No entanto, a mesma legislação observa poucos aspectos da segurança física, e não dispõem quais as ações que devem ser adotadas nos casos mencionados.

Fontes bibliográficas internacionais que tratam da segurança física do depósito são mais específicas. Uma delas aponta os principais riscos e faz recomendações sobre as soluções que podem ser adotadas [41].

Durante as visitas aos SMN foi observado que a infra-estrutura dispensada para a segurança física dos depósitos considera basicamente riscos de acesso indevido por pessoas e de incêndio, contra os quais empregam diferentes recursos.

Os SMN A, B e D fazem o controle de acesso na recepção durante o período de funcionamento e após esse período ficam trancados e sob vigilância constante, controlados pela equipe de segurança do edifício onde estão instalados. A proteção contra incêndio desses SMN é feita pela brigada contra incêndio do edifício.

Os SMN C e E fazem seu controle de acesso na recepção durante o período de funcionamento e após esse período são trancados, sem vigilância constante. O SMN E faz uso de um sistema de alarme contra intrusão de pessoas ativado por sensores de movimento. Os SMN C e E tem localizado dentro do laboratório um extintor contra incêndio.

O depósito de armazenamento de rejeitos radioativos deve ser construído e operado, considerando sua segurança física. Os riscos potenciais relacionados a este quesito são: acesso indevido, incêndio e invasão de animais.

A remoção desautorizada de rejeitos radioativos deve ser impedida. Para isso deve haver mecanismos de segurança adequados para impedir o acesso de pessoas desautorizadas. Sugere-se a restrição de acesso de pessoas por meio de controle de acesso na recepção do hospital ou SMN. Também é recomendado $\mathrm{o}$ uso de barreiras físicas por meio de chaves, fechaduras e cadeados. A abertura do depósito de rejeitos deverá ser feita somente por pessoas autorizadas e em ocasiões justificáveis de controle, deposição ou liberação de rejeitos radioativos. 
Se o SMN estiver instalado em um local que ofereça vigilância controlada por seguranças de forma contínua, não se faz necessário outros recursos de segurança física além dos citados acima. Caso contrário é recomendável, após o expediente, a utilização de um sistema de alarme contra possíveis intrusões. O mais comum é o uso de alarme acoplado a sensores de movimento.

Os materiais usados na construção do depósito de rejeitos devem possuir características não inflamáveis de modo a minimizar a propagação de fogo em caso de incêndio.

O serviço de medicina nuclear deve possuir um plano contra incêndio regulamentado pelo corpo de bombeiros. Recomenda-se que sejam usados extintores de incêndio de pó químico seco, visando minimizar a dispersão da contaminação, e que estes estejam localizados no exterior do depósito de rejeitos radioativos.

O depósito de rejeitos radioativos deve ser equipado com sistema de detecção de incêndio, podendo ser um detector de fumaça ou um sensor de temperatura.

O número do telefone de contato do corpo de bombeiros deve estar fixado na parte externa da porta do depósito, como mencionado no tópico 5.3.

Em caso de incêndio não controlável deverá ser acionado o corpo de bombeiros e o responsável pela proteção radiológica da instalação que por sua vez entrará em contato com a CNEN. O responsável pela instalação deverá alertar os bombeiros para manterem-se o mais afastado possível das fontes, usarem o mínimo de água para diminuir o risco de contaminação e utilizar o mínimo de pessoas. Os bombeiros deverão usar protetores para respiração, de preferência do tipo de circuito fechado.

Invasões de animais de pequeno porte como insetos e roedores podem apresentar uma séria ameaça aos rejeitos radioativos que estão contidos nos embalados, principalmente para os embalados de saco plástico que podem ser rompidos sem muita dificuldade.

Ações contra estes tipos de animais são particularmente importantes onde resíduos biológicos e rejeitos radioativos são armazenados. O consumo e dispersão através da excreta desses animais podem resultar na propagação da contaminação radioativa e de materiais potencialmente infecciosos. Um programa 
de controle contra essa infestação, para o depósito de rejeitos radioativos, deve ser realizado com a cooperação de órgãos autorizados a tratar desse problema, e ir ao encontro a todas as exigências aplicáveis. Os problemas com animais devem ser identificados e avaliados, incluindo os custos para eliminá-los.

Devem ser realizadas medidas para avaliar e reduzir as rotas de entrada de animais no depósito de rejeito radioativo. Qualquer deficiência relacionada à construção, que permita a entrada de animais, deve ser reparada.

O depósito de rejeitos radioativos não deve possuir frestas em suas extremidades e nem estar localizado próximo a áreas de alimentação ou de locais onde depositem resíduos de alimentação, para que não haja estímulo de infestação de animais. Além das medidas preventivas contra tais animais pode-se fazer uso de venenos que devem ser colocados dentro e fora do depósito de rejeito radioativo.

O uso de armadilhas pode ser considerado onde a população de animais tenha desenvolvido resistência a produtos químicos, e quando há evidência que estes intrusos estão espalhando a contaminação.

\subsection{Revestimento de piso e paredes}

Aspectos como textura de paredes e piso a fim de minimizar uma possível contaminação de superfície devem ser observados. A CNEN determina que o depósito de rejeitos deve "ter piso e paredes impermeáveis e de fácil descontaminação" [7]. Entretanto, a legislação nacional não faz descriminação dos materiais de construção que podem ser usados.

Recomendações internacionais também não especificam os materiais de construção que podem ser usados. A esse respeito recomendam apenas que os pisos localizados em áreas com potencial risco de contaminação devem ser revestidos por materiais impermeáveis e laváveis [41].

Nas visitas foi observado variação no revestimento das superfícies internas dos depósitos de rejeitos. Os depósitos visitados possuíam suas paredes e pisos revestidos de azulejo ou porcelanato unidos por rejunte à base de cimento ou ainda revestidos com placas de Paviflex®.

O uso desses materiais não é recomendado, pois as junções entre as peças de azulejo, porcelanato ou Paviflex® são de fácil absorção de líquido, o que dificultaria uma possível descontaminação 
Uma opção viável para o revestimento das superfícies dos depósitos de rejeitos é a pintura feita com tinta de base sintética epóxi. As paredes do depósito devem possuir os cantos arredondados e serem pintadas até a altura do teto, ou a uma altura mínima de dois metros e trinta. A FIG. 10 apresenta o detalhe de piso e paredes com cantos arredondados pintada com tinta de base epóxi.

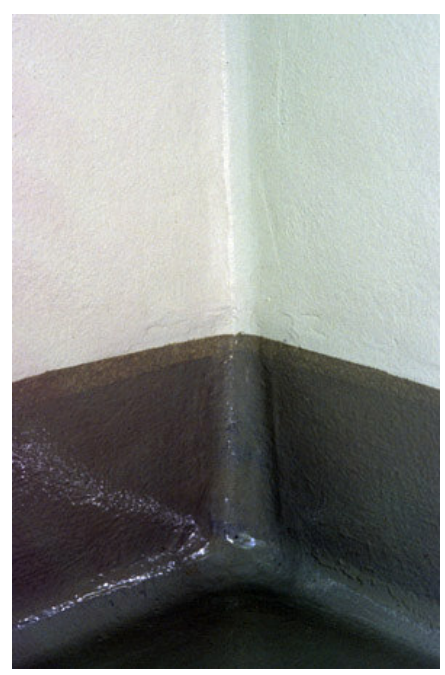

FIGURA 10 - Exemplo de revestimento de paredes e piso à base de tinta epóxi

\subsection{Treinamento}

As Normas da CNEN exigem que os SMN apresentem em seu plano de radioproteção a forma de "seleção e treinamento do pessoal, onde devem ser estabelecidos critérios de seleção, programas de treinamento específicos e programas de reciclagem" [17]. Sendo que "O supervisor de radioproteção é responsável pela execução do programa de treinamento dos trabalhadores, conforme descrito no plano de radioproteção, e pela contínua avaliação de sua eficácia com relação às condições radiológicas da instalação e grau de aprendizagem dos trabalhadores" [45]. Ainda é obrigação do supervisor de radioproteção "tomar as ações necessárias para assegurar que os IOE (Indivíduos Ocupacionalmente Expostos) estejam cientes de que sua segurança é parte integrante de um programa de proteção radiológica, no qual os IOE possuem obrigações e responsabilidades tanto pela sua própria proteção como pela de terceiros" [46]. 
Várias recomendações internacionais tratam sobre treinamento de radioproteção para funcionários de SMN, sendo mais específicas que a legislação nacional. Muitas delas descrevem os temas que devem ser abordados, entre os quais a gerência de rejeitos radioativos [21, 41, 44].

Todos os SMN visitados apresentavam como parte do seu plano de radioproteção um programa de treinamento de quarenta horas, destinado aos IOE, entretanto nenhum deles considerava a gestão de rejeitos radioativos como parte do programa de treinamento.

A periodicidade dos treinamentos dos SMN A, B, D e E é anual, ou na ocorrência de algum fato anormal. O SMN C oferece o curso de reciclagem semestralmente.

O presente trabalho recomenda que a gestão de rejeitos radioativos seja parte integrante nos treinamentos de proteção radiológica. Esse treinamento deve assegurar que todos os trabalhadores envolvidos direta ou indiretamente em alguma das etapas da produção de rejeitos radioativos, compreendam a natureza dos riscos provenientes dos rejeitos quando são geridos de forma incorreta.

No treinamento sobre gestão de rejeitos radioativos deverão ser abordados os aspectos referentes à minimização da geração de rejeitos, os aspectos operacionais da gestão como coleta, segregação, identificação e acondicionamento, bem como os aspectos administrativos, como registros e controle. O treinamento é recomendado na admissão do funcionário com reciclagem a cada ano para atualização das boas práticas.

\subsection{Segregação e embalagem}

A minimização do volume de rejeitos radioativos gerados em uma instalação pode ser alcançada por meio de projetos e de práticas adequadas, incluindo a seleção e o controle de materiais, a reciclagem/reutilização e a implementação de procedimentos apropriados, dentre os quais destaca-se a segregação dos diferentes tipos de rejeitos e materiais para reduzir o volume e facilitar a gerência dos rejeitos.

A CNEN define segregação como "separação dos rejeitos, de acordo com suas características físicas, químicas, biológicas e radiológicas, de modo a facilitar a gerência" e no capítulo cinco de sua Norma CNEN-NE-6.05 apresenta os critérios que devem ser seguidos para a segregação e algumas características 
dos recipientes utilizados para acomodar os rejeitos [7]. Alguns critérios, porém excluem determinados tipos de rejeitos. É o caso dos rejeitos com meia-vida inferior a 60 dias que abrange a maioria dos radionuclídeos empregados em SMN.

Uma das recomendações do OIEA é a segregação dessa classe de rejeitos da seguinte forma [41]:

- rejeitos com meia-vida igual ou inferior a dez horas (T1/2 $\leq 10$ horas);

- rejeitos com meia-vida igual ou inferior a dez dias (T1/2 $\leq 10$ dias);

- rejeitos com meia-vida igual ou inferior a cem dias (T1/2 $\leq 100$ dias);

- rejeitos com meia-vida igual ou superior a 100 dias (T1/2 $\geq 100$ dias).

Nas visitas realizadas foi observado que todos os SMN cumpriam as exigências da CNEN no que diz respeito às etapas de coleta e segregação na origem, considerando as características físicas, químicas, biológicas, radiológicas e na identificação. Mesmo assim as unidades apresentavam bastante variação nesses aspectos quando comparadas umas com as outras.

Todos os SMN visitados fazem sua segregação individual segundo o radionuclídeo presente no rejeito, exceto o SMN D, que deposita rejeitos com diferentes radionuclídeos em um mesmo embalado.

Em relação às embalagens, a legislação nacional menciona que "Os recipientes para segregação, coleta ou armazenamento provisório devem ter adequados às características físicas, químicas, biológicas e radiológicas dos rejeitos para os quais são destinados." [7]. No entanto, não há discriminação das embalagens que podem ser usadas para esse fim. Algumas recomendações internacionais são mais especificas, porém, diferem uma das outras dependendo dos limites de isenção adotados por cada país [44].

Todos os SMN consideram as características físicas dos rejeitos no momento de segregação, e os depositam em embalagens com as seguintes características:

- Rejeitos perfuro-cortantes são colocados em caixa de papelão apropriadas;

- Rejeitos com características compactáveis são colocados em sacos plásticos de cor branca;

- Rejeitos com características não compactáveis são colocados em sacos plásticos de cor branca. 
Apenas o SMN C segrega rejeitos líquidos inorgânicos (restos de radioisótopos contidos nos frascos originais, após sua utilização) e para isso utiliza o próprio frasco.

A segregação por radionuclídeo é recomendada, uma vez que se utiliza apenas um radionuclídeo por procedimento. No caso de acondicionamento em um único recipiente, de rejeitos com dois ou mais isótopos diferentes, é recomendado que se considere para fatores de cálculo de decaimento o isótopo com a maior meia-vida.

Os rejeitos devem ser segregados segundo suas características físicas em dois grupos, rejeitos sólidos com características perfuro-cortantes e rejeitos sólidos.

Para coleta de rejeito sólido recomenda-se o uso de recipientes metálicos com pedal, forrado com saco plástico reforçado $(0,08$ a $0,2 \mathrm{~mm}$ de espessura) e para coleta de rejeitos sólidos com características cortantes e perfurantes o uso de caixas de papelão específicas para perfuro-cortantes.

Os restos de radiofármaco contidos nos frascos após a utilização devem ser liberados na rede de esgoto sanitário, preferencialmente, na pia localizada dentro do laboratório de manipulação. Os frascos devem ser tratados como rejeito sólido.

\subsection{Identificação da embalagem}

A Norma CNEN-NE-6.05 determina que "após a segregação e acondicionamento em recipientes adequados, os rejeitos devem ser identificados...", e exige também que os dados sejam registrados [7]. Para as duas finalidades a norma disponibiliza um modelo.

Referências internacionais também trazem recomendações sobre identificação das embalagens de rejeitos e seu registro. Porém, apresentam diferenças na forma de identificação e registro, quando comparados com o modelo apresentado na legislação nacional [41].

Todos os SMN visitados usam adesivos ou etiquetas na identificação dos embalados. Nestes constam informações dos rejeitos conforme o modelo disponibilizado pela CNEN. Os registros dos rejeitos também são feitos conforme o modelo apresentado na Norma. 
O modelo de etiqueta de identificação estabelecido em Norma apresenta o símbolo universal de radiação e informações sobre o rejeito, como origem, responsável pela radioproteção, nome da instalação, características físicas, radionuclídeos presentes, atividade, taxa de dose e etc.

A sugestão desse trabalho é que a identificação da embalagem seja feita com uma etiqueta adesiva, e nesta conste somente o símbolo universal de radiação claramente visível seguido das informações: número da etiqueta, taxa de dose, data de liberação.

O número da embalagem serve para que a mesma seja rastreada. A numeração da embalagem deve constar nos registros de rejeitos junto com outras informações, conforme recomendado em norma.

A etiqueta deve possuir um tamanho que facilite sua visualização, de forma que o indivíduo que for fazer o controle não se aproxime muito. O presente trabalho recomenda que a etiqueta tenha dimensões de $10 \times 10 \mathrm{~cm}$. Na FIG. 11 apresenta-se a ilustração de uma etiqueta de identificação para embalagens de rejeitos.

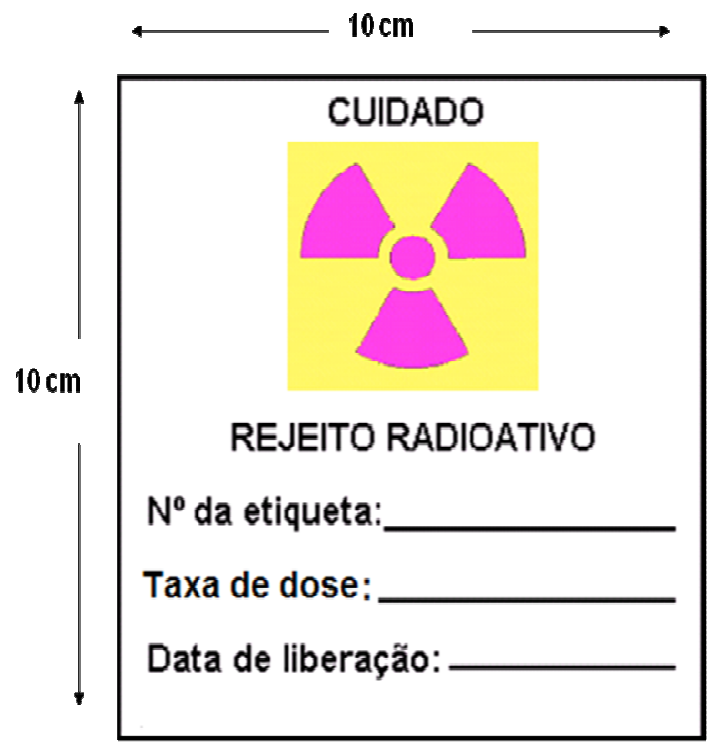

FIGURA 11 - Modelo de etiqueta para identificação de rejeito radioativo 


\subsection{Dimensão do depósito}

Após segregação, acondicionamento, identificação e registro, os rejeitos radioativos devem ser colocados em uma área específica da instalação, comumente chamada de sala de rejeitos radioativos. Este local visa o armazenamento dos rejeitos para decaimento ou para futura remoção para um dos Institutos da CNEN.

A CNEN não dispõe sobre quais são os recursos apropriados que um depósito de rejeitos radioativos utilizado em SMN deva possuir. O OIEA aborda de forma mais descritiva este tema [41].

Todos os SMN visitados dispunham de recursos para a acomodação dos rejeitos dentro do depósito.

O SMN A possui um depósito de rejeitos com dimensões internas aproximadas de $9 \mathrm{~m}^{2}$. Em seu interior há uma estante de metal com dimensões de 1,5 $\mathrm{m}$ de largura e $2 \mathrm{~m}$ de altura. Que acomoda as embalagens de rejeitos uma ao lado da outra, de forma que suas etiquetas de identificação ficam sempre voltadas para frente, facilitando assim sua visualização.

O SMN B possui um depósito de rejeitos com uma área aproximada de $16 \mathrm{~m}^{2}$. Seu interior tem duas caixas de madeira com tampa, ambas com espaço interno de $3 \mathrm{~m}^{2}$. As embalagens de rejeitos são acomodadas nestas caixas de forma aleatória, umas sobre as outras, não facilitando a visualização de suas identificações.

O SMN C possui dois locais para armazenamento de rejeitos. O primeiro depósito possui área aproximada de $3 \mathrm{~m}^{2}$. Em seu interior há uma caixa com tampa, feita a base de cimento com espaço interno de $2,25 \mathrm{~m}^{2}$, onde são depositados os rejeitos. O segundo local, utilizado para armazenamento de rejeitos, é uma caixa com tampa feita a base de cimento. Ela possui espaço interno de $4 \mathrm{~m}^{2}$, onde as embalagens de rejeitos são acomodadas de forma aleatória umas sobre as outras. Esta caixa está localizada em uma sala fora do SMN.

O depósito de rejeitos, além das recomendações de construção já citadas, deve dispor de recursos físicos que permitam o controle dos rejeitos, mantendo a integridade física e contábil dos recipientes que os contém, até sua eliminação ou transferência para um dos Institutos da CNEN. 
O depósito deve possuir recursos para facilitar a acomodação dos rejeitos gerados. Para isso pode-se usar estantes ou caixa com tampa, sendo esta constituída de material blindante, com superfícies externa e interna revestidas com material lavável, impermeável e com divisórias.

O depósito também deve possuir um tamanho que comporte a demanda de rejeitos gerados pelo SMN. Um depósito com uma área de $3 \mathrm{~m}^{2}$ $(1,50 \mathrm{~m} \times 2 \mathrm{~m})$, que dispõe de uma estante com três prateleiras terá capacidade de armazenar um volume aproximado de $500 \mathrm{~L}$ de rejeitos produzidos por mês. A FIG. 12 ilustra um depósito com uma área de 1,50m x 2m.

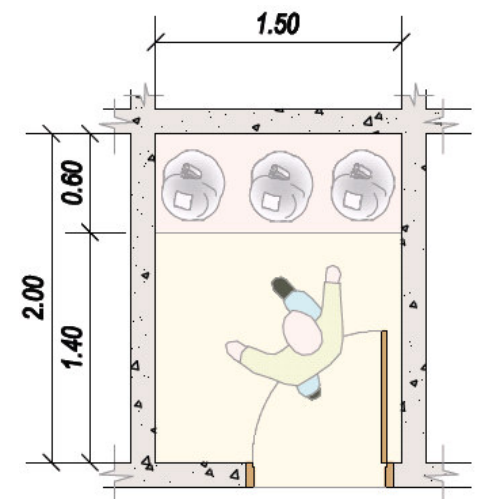

FIGURA 12 - Depósito de rejeitos com área de 1,50m x 2m

Um depósito com dimensão de $2 \mathrm{~m} \times 2 \mathrm{~m}\left(4 \mathrm{~m}^{2}\right)$, dispondo de duas estantes, ambas com duas prateleiras, terá capacidade de armazenar um volume aproximado de $900 \mathrm{~L}$ de rejeitos produzidos por mês. Na FIG. 13 apresenta-se a ilustração de um depósito com uma área de $4 \mathrm{~m}^{2}$.

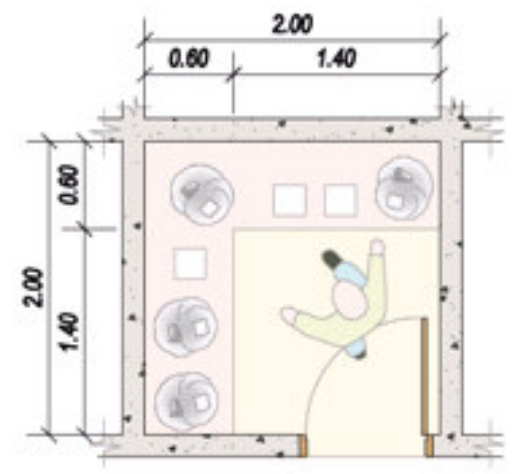

FIGURA 13 - Depósito de rejeitos com área de $4 \mathrm{~m}^{2}$ 
Um depósito com $9 \mathrm{~m}^{2}$ (3,40m x 2,65m) que disponha de três estantes, todas com três prateleiras terá capacidade de armazenar um volume aproximado de $1900 \mathrm{~L}$ de rejeitos produzidos por mês. A FIG.14 apresenta as ilustrações de um depósito com uma área de $9 \mathrm{~m}^{2}$.
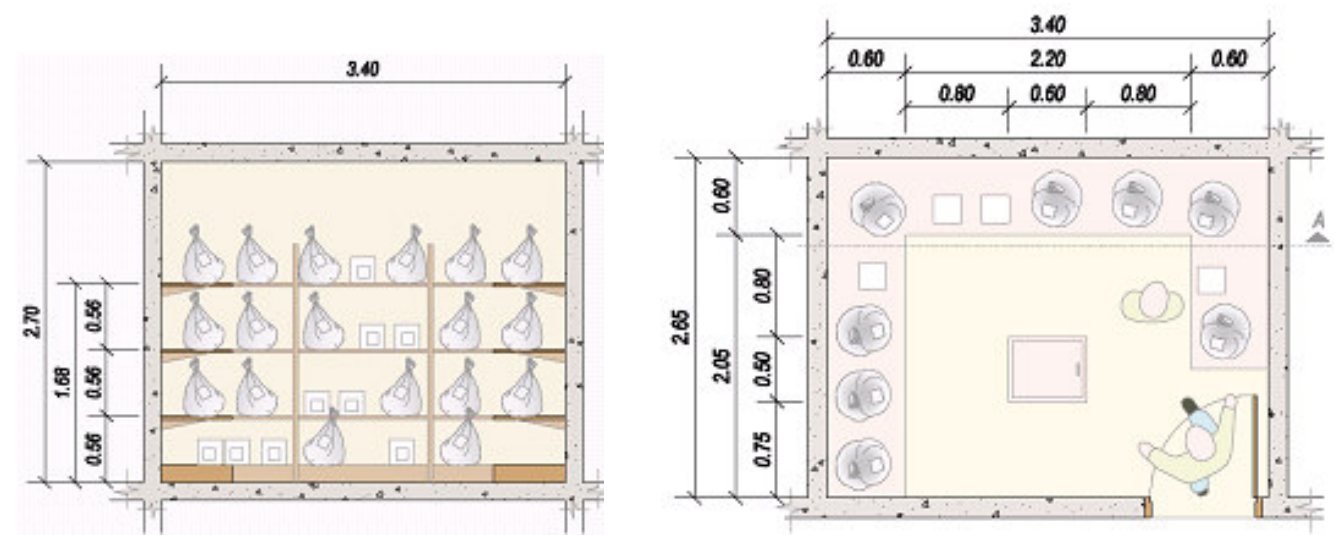

FIGURA 14 - Depósito de rejeitos com área de $9 \mathrm{~m}^{2}$ 


\section{COMENTÁRIOS E CONCLUSÕES}

A operação de $S M N$ deve obedecer aos requisitos de segurança radiológica estabelecidos pela CNEN, entre os quais, a norma CNEN-NE-6.05 Gerência de rejeitos radioativos em instalações radiativas. Essa norma contém uma série de requisitos para a implantação e operação de um sistema de gestão dos rejeitos radioativos em uma instalação radiativa. Ainda que sejam chamados de "normas" pela própria CNEN, esses documentos são, na prática, regulamentos com força de lei, aos quais todas as instalações radiativas licenciadas estão obrigadas a submeter-se.

Não há dúvidas que este documento é um marco relacionado à gestão dos rejeitos radioativos e ajuda em grande parte no papel de orientar no projeto e operação de um sistema de gestão de rejeitos em instalações usuárias de radioisótopos. No entanto, por tratar de diferentes tipos de instalações acaba abordando de forma generalizada, não considerando aspectos particulares das diferentes instalações, como é o caso dos SMN.

Muitos aspectos dos regulamentos que foram discutidos no presente trabalho evidenciam que a legislação aplicada à gestão de rejeitos em SMN apresenta inconsistências que dificultam o projeto e a operação da instalação e a documentação do pedido de licença.

Os resultados e discussões apresentados neste trabalho mostraram-se uma opção viável no auxílio do cumprimento das exigências regulatórias de um sistema de gerência de rejeitos radioativos em um SMN de classe 2 . 


\section{APÊNDICE - A}

\section{PROCEDIMENTOS PARA GESTÃO DE REJEITOS}

RADIOATIVOS EM SERVIÇOS DE MEDICINA NUCLEAR 


\section{A. INTRODUÇÃO}

A Medicina Nuclear é uma especialidade médica que se ocupa das técnicas de diagnóstico e terapia utilizando substâncias radioativas em forma de fontes abertas. Estas substâncias radioativas são administradas aos pacientes por inalação, via oral ou endovenosa. Para cada uma das técnicas são produzidos e utilizados radiofármacos específicos que permitem o diagnóstico ou terapia de um grande número de doenças, especialmente o câncer. A utilização dessas substâncias radioativas irá eventualmente gerar rejeitos radioativos.

A Norma CNEN-NE-6.05 "Gerência de rejeitos radioativos em instalações radiativas", em seu capítulo cinco, apresenta uma série de requisitos para a operação de um sistema de gestão dos rejeitos radioativos, incluindo exigências para as edificações, os equipamentos e os materiais utilizados para a embalagem, transporte e armazenamento dos rejeitos e também exigências para aspectos administrativos do sistema, como registro e arquivamento, treinamento e credenciamento de pessoal, autorização de descarte entre outros.

\section{B. FLUXOGAMA DA GERÊNCIA DE REJEITOS RADIOATIVOS}

A segregação dos rejeitos radioativos deve ser feita em categorias prédefinidas durante a sua coleta. A maior parte dos rejeitos gerados em SMN tem meia-vida curta e o armazenamento seguro em local adequado e exclusivo deve ser feito até que sua atividade alcance limites de liberação. Rejeitos que possuem tempo de meia-vida maior que 60 dias devem ser transferidos para um dos institutos da CNEN. A FIG. 1 apresenta um esquema resumido da gerência de rejeitos radioativos.

Os rejeitos radioativos assim que gerados devem ser imediatamente segregados, acondicionados, classificados, identificados, registrados e armazenados. Aqueles rejeitos que estiverem com sua atividade abaixo dos limites de isenção deverão ter o mesmo destino que o lixo comum da instalação. Materiais e equipamentos ainda úteis devem ser descontaminados para reutilização, reduzindo sempre que possível, o volume de rejeitos gerados. 


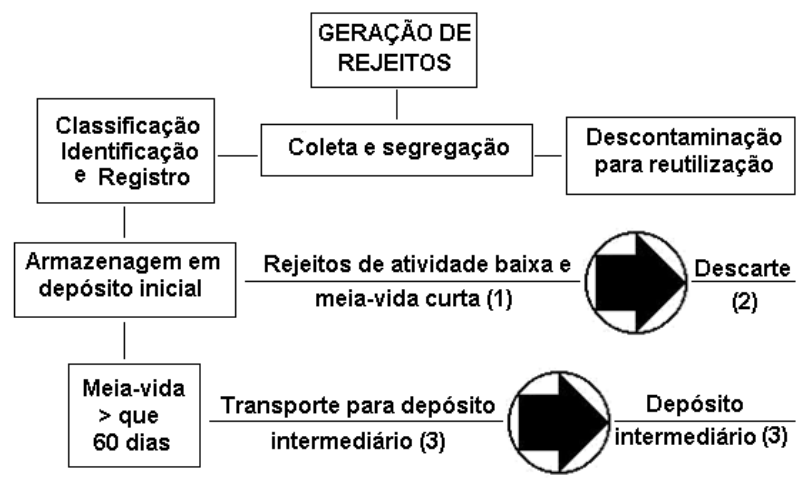

(1) atividade inferior ao limite estabelecido em regulamento

(2) líquido no esgoto; sólido mesmo tratamento que o lixo hospitalar

(3) um dos Institutos da Comissão Nacional de Energia Niclear

FIGURA 1 - Fluxograma genérico da gestão de rejeitos radioativos em SMN

\section{LOCALIZAÇÃO DO DEPÓSITO}

O objetivo do depósito de rejeitos é manter o rejeito radioativo sob controle de forma que permita uma liberação controlada dos rejeitos que alcançarem os níveis de liberação, ou serem transferidos para um dos institutos da CNEN. A localização do depósito depende da quantidade de rejeito a ser armazenado, podendo ser um cofre blindado no próprio laboratório ou uma sala preparada e dedicada exclusivamente para o armazenamento de rejeito.

No caso da sala dedicada ao armazenamento de rejeitos radioativos, o local para o armazenamento deve ser o mais próximo da sala de manipulação de radioisótopos, se possível tendo interligação entre eles. A localização próxima tem a finalidade de diminuir o percurso de transporte do rejeito, restringir o perímetro de possíveis acidentes e centralizar a manipulação do material radioativo.

\section{TRANSPORTE INTERNO DE REJEITOS RADIOATIVOS}

O transporte do rejeito radioativo é requerido, sempre que se for remover o rejeito radioativo do local onde ele é produzido até o local onde será armazenado. Em casos de volumes consideráveis de rejeitos será empregado veículo para o transporte interno dos mesmos.

É recomendado que o modo de transporte e o itinerário sejam planejados, de forma que o número de viagens e o tempo no qual a carga fique 
em trânsito sejam reduzidos ao mínimo. Esse procedimento deve ser feito em horários de menor movimento e não coincidentes com a distribuição de roupas, alimentos e medicamentos, períodos de visita e se possível, no final do expediente de trabalho.

Antes da acomodação dos embalados de rejeitos no veículo deve-se observar se estes estão intactos e sejam capazes de suportar as condições de transporte sem extravasar seu conteúdo.

O veículo utilizado no transporte de rejeitos deve possuir as seguintes características:

- ser de fácil manuseio, levando-se em consideração a massa, o volume e a geometria do mesmo;

- ter sua superfície externa livre de saliências, com bordas e cantos arredondados, de forma a poder ser facilmente descontaminado;

- ser constituído de material rígido, lavável e impermeável;

- $\quad$ ser provido de tampa;

- ser provido de rodas revestidas de material que reduza trepidações;

- possuir o símbolo internacional de presença de radiação ionizante (trifólio de cor preta ou magenta) em rótulos de fundo amarelo e contornos pretos, acrescido da expressão "REJEITO RADIOATIVO", em local de fácil visualização;

- possuir tamanho que comporte os rejeitos gerados diariamente pela instalação de forma que diminua o máximo possível o número de viagens;

- não ser utilizado para armazenamento ou transporte de outras mercadorias;

- suportar possíveis choques mecânicos;

- ter capacidade de reter fluidos em seu interior e não possuir válvula de drenagem no fundo;

- ser manipulado, exclusivamente, por funcionários autorizados, treinados e informados sobre os riscos radiológicos associados ao transporte;

- ter fixados em sua tampa as rotas e os horários de transporte. 


\section{E. SINALIZAÇÃO E FIXAÇÃO DE PROCEDIMENTOS}

A norma CNEN-NE-6.05 determina que o local destinado ao armazenamento provisório de rejeitos tenha todos os procedimentos pertinentes fixados em paredes, quadros e outros lugares bem visíveis.

Devem ser adotados procedimentos padrão em situações normais e acidentais. São consideradas situações normais, as situações em que a fonte radiativa está controlada e a exposição pode ser limitada com o emprego de medidas adequadas de controle. Situações acidentais são aquelas em que se perde o controle sobre a fonte de radiação e a exposição, portanto, deve ser limitada unicamente com medidas corretivas.

Para que se adotem procedimentos para situações normais e ou acidentais faz-se necessário conhecer a rotina da instalação, os rejeitos radioativos que são gerados, o tratamento dado a eles, bem como prever os possíveis acidentes. Assim sendo é possível planejar e estabelecer condutas padrão em situações normais e acidentais.

É recomendado que o local escolhido do depósito para a fixação de procedimentos para as duas situações seja na parte interna e externa da porta do depósito.

Deve estar fixado do lado externo da porta do depósito, além do símbolo internacional de radiação ionizante, os números de telefone do serviço de radioproteção da unidade, do plantão de emergência do instituto da CNEN mais próximo, do corpo de bombeiros e da polícia e os seguintes avisos:

- Área restrita;

- Proibida a entrada de pessoas não autorizadas;

A parte interna da porta do depósito deve estar sinalizada com os seguintes avisos:

- Permanecer dentro do depósito apenas o tempo necessário para a realização dos procedimentos;

- Manter-se a maior distância possível dos rejeitos ao manuseá-los;

- Posicionar o rejeito de forma que a etiqueta de identificação seja de fácil visualização;

- Cuidar para não misturar os rejeitos radioativos com características diferentes. 
A fixação de procedimentos também é recomendada para locais onde há maior manipulação de radioisótopos, e outros locais onde ainda exista risco de contaminação.

\section{F. SEGURANÇA FÍSICA DO DEPÓSITO DE REJEITOS RADIOATIVOS}

O depósito de armazenamento de rejeitos radioativos deve ser construído e operado, considerando sua segurança física. Os riscos potenciais relacionados à segurança física de um depósito de rejeitos radioativos são de acesso indevido, de incêndio e de invasão de animais.

A remoção desautorizada de rejeitos radioativos deve ser impedida. Para isso deve haver mecanismos de segurança adequados para impedir o acesso de pessoas desautorizadas. Sugere-se a restrição de acesso de pessoas por meio de controle de acesso na recepção do hospital ou SMN. Também é recomendado o uso de barreiras físicas por meio de chaves, fechaduras e cadeados. A abertura do depósito de rejeitos deverá ser feita somente por pessoas autorizadas e em ocasiões justificáveis de controle, deposição ou liberação de rejeitos radioativos.

Se o SMN estiver instalado em um local que ofereça vigilância controlada por seguranças de forma contínua, não se faz necessário outros recursos de segurança física além dos citados acima. Caso contrário é recomendável, após o expediente, a utilização de um sistema de alarme contra possíveis intrusões. O mais comum é o uso de alarme acoplado a sensores de movimento.

Os materiais usados na construção do depósito de rejeitos devem possuir características não inflamáveis de modo a minimizar a propagação de fogo em caso de incêndio.

O serviço de medicina nuclear deve possuir um plano contra incêndio regulamentado pelo corpo de bombeiro. Recomenda-se que sejam usados extintores de incêndio de pó químico seco, visando minimizar a dispersão da contaminação, e que estes estejam localizados no exterior do depósito de rejeitos radioativos. 
O depósito de rejeitos radioativos deve ser equipado com sistema de detecção de incêndio, podendo ser um detector de fumaça ou um sensor de temperatura.

O número do telefone de contato do corpo de bombeiros deve estar fixado na parte externa da porta do depósito.

Em caso de incêndio não controlável deverá ser acionado o corpo de bombeiros e o responsável pela proteção radiológica da instalação que por sua vez entrará em contato com a CNEN. O responsável pela instalação deverá alertar os bombeiros para manterem-se o mais afastado possível das fontes, usarem o mínimo de água para diminuir o risco de contaminação e utilizar o mínimo de pessoas. Os bombeiros deverão usar protetores para respiração, de preferência do tipo de circuito fechado.

Invasões de animais de pequeno porte como insetos e roedores podem apresentar uma séria ameaça aos rejeitos radioativos que estão contidos nos embalados, principalmente para os embalados de saco plástico que podem ser rompidos sem muita dificuldade.

Ações contra estes tipos de animais são particularmente importantes onde resíduos biológicos e rejeitos radioativos são armazenados. O consumo e dispersão através da excreta desses animais podem resultar na propagação da contaminação radioativa e de materiais potencialmente infecciosos. Um programa de controle contra essa infestação, para o depósito de rejeitos radioativos, deve ser realizado com a cooperação de órgãos autorizados a tratar desse problema, e ir ao encontro a todas as exigências aplicáveis. Os problemas com animais devem ser identificados e avaliados, incluindo os custos para eliminá-los.

Devem ser realizadas medidas para avaliar e reduzir as rotas de entrada de animais no depósito de rejeito radioativo. Qualquer deficiência relacionada à construção, que permita a entrada de animais, deve ser reparada.

O depósito de rejeitos radioativos não deve possuir frestas em suas extremidades e nem estar localizado próximo a áreas de alimentação ou de locais onde depositem resíduos de alimentação para que não haja estímulo de infestação de animais. Além das medidas preventivas contra tais animais pode-se fazer uso de venenos que devem ser colocados dentro e fora do depósito de rejeito radioativo. 
O uso de armadilhas pode ser considerado onde a população de animais tenha desenvolvido resistência a produtos químicos, e quando há evidência que estes intrusos estão espalhando a contaminação.

\section{G. REVESTIMENTO DE PISOS E PREDES}

Aspectos como textura de paredes e piso a fim de minimizar uma possível contaminação de superfície devem ser observados. A opção recomendada para o revestimento das superfícies dos depósitos de rejeitos é a pintura feita com tinta de base sintética epóxi. As paredes do depósito devem possuir os cantos arredondados e serem pintadas até a altura do teto, ou a uma altura mínima de dois metros e trinta. A FIG. 2 apresenta o detalhe de piso e paredes com cantos arredondados pintada com tinta de base epóxi.

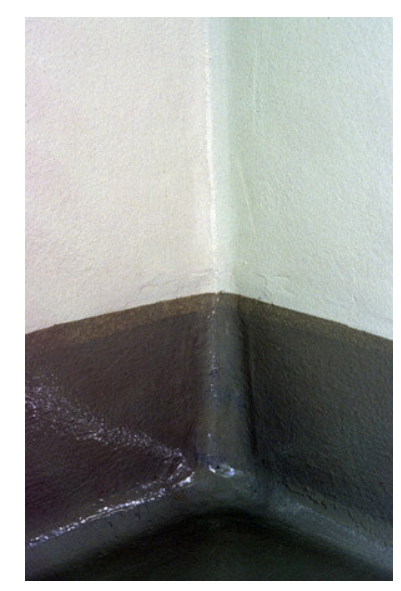

FIGURA 2 - Exemplo de revestimento de paredes e piso à base de tinta epóxi

\section{H. TREINAMENTO}

A gestão de rejeitos radioativos deve ser parte integrante nos treinamentos de proteção radiológica. Esse treinamento deve assegurar que todos os trabalhadores envolvidos direta ou indiretamente em alguma das etapas da produção de rejeitos radioativos, compreendam a natureza dos riscos provenientes dos rejeitos quando são geridos de forma incorreta.

No treinamento sobre gestão de rejeitos radioativos deverão ser abordados os aspectos referentes à minimização da geração de rejeitos, aos 
aspectos operacionais da gestão como coleta, segregação, identificação e acondicionamento, bem como aos aspectos administrativos como registros e controle. O treinamento é recomendado na admissão do funcionário com reciclagem a cada ano para atualização das boas práticas.

\section{SEGREGAÇÃO E EMBALADOS}

A minimização do volume de rejeitos radioativos gerados em uma instalação pode ser alcançada por meio de projetos e de práticas adequadas, incluindo a seleção e o controle de materiais, a reciclagem/reutilização e a implementação de procedimentos apropriados, dentre os quais destaca-se a segregação dos diferentes tipos de rejeitos e materiais para reduzir o volume e facilitar a gerência dos rejeitos.

É recomendado que a segregação por radionuclídeo seja individual, uma vez que se utiliza apenas um radionuclídeo por procedimento. No caso de acondicionamento, em um único recipiente, de rejeitos com dois ou mais isótopos diferentes é recomendado que se considere para fatores de cálculo de decaimento o isótopo com a maior meia-vida.

Quanto a segregação segundo as características físicas do rejeito, o presente trabalho recomenda que os rejeitos sejam segregados em dois grupos, rejeitos sólidos com características perfuro-cortantes e rejeitos sólidos.

Para coleta de rejeito sólido recomenda-se o uso de recipientes metálicos com pedal, forrado com saco plástico reforçado $(0,08$ a $0,2 \mathrm{~mm}$ de espessura) e para coleta de rejeitos sólidos com características cortantes e perfurantes o uso de caixas de papelão específicas para perfuro-cortantes.

Os restos de radiofármaco contidos nos frascos após a utilização devem ser liberados na rede de esgoto sanitário, preferencialmente na pia localizada dentro do laboratório de manipulação, os frascos devem ser tratados como rejeito sólido. 


\section{J. IDENTIFICAÇÃO DA EMBALAGEM}

A identificação da embalagem deve ser feita com uma etiqueta adesiva, e nesta deve haver o símbolo da radiação claramente visível seguido das informações; número da etiqueta, taxa de dose, data de liberação.

$\mathrm{O}$ número da embalagem serve para que a mesma seja rastreada. A numeração da embalagem deve constar nos registros de rejeitos junto com outras informações, conforme recomendado em norma. A etiqueta deve possuir um tamanho que facilite sua visualização, de forma que o indivíduo que for fazer o controle não se aproxime muito. A etiqueta deve possuir dimensões de $10 \times 10$ cm. Na FIG. 3 apresenta-se a ilustração de uma etiqueta de identificação para embalagens de rejeitos.

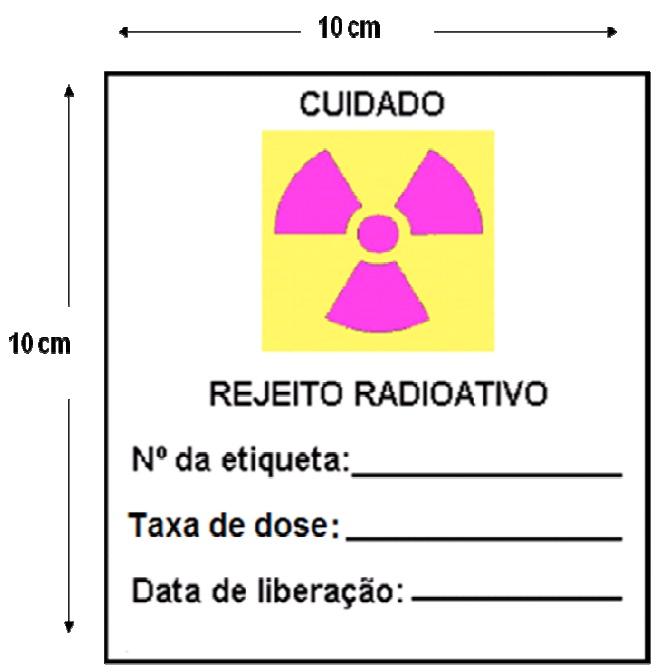

FIGURA 3 - Modelo de etiqueta para identificação de rejeito radioativo

\section{K. DIMENSÃO DO DEPÓSITO}

Após segregação, acondicionamento, identificação e registro, os rejeitos radioativos devem ser colocados em uma área específica da instalação, comumente chamada de sala de rejeitos radioativos. Este local visa o armazenamento dos rejeitos para decaimento ou para futura remoção para um dos Institutos da CNEN.

Este local, além das recomendações de construção já citadas, deve dispor de recursos físicos que permitam o controle dos rejeitos, mantendo a 
integridade física e contábil dos recipientes que os contém, até sua eliminação ou transferência para um dos Institutos da CNEN.

O depósito deve possuir recursos para facilitar a acomodação dos rejeitos gerados, para isso pode-se usar estantes, caixa com tampa, sendo esta constituída de material blindante, com superfícies externa e interna revestidas com material lavável, impermeável e com divisórias. O depósito também deve possuir um tamanho que comporte a demanda de rejeitos gerados pelo SMN.

Um depósito que tenha uma área de $3 \mathrm{~m}^{2}$, que disponha de uma estante com três prateleiras terá capacidade de armazenar um volume aproximado de $500 \mathrm{~L}$ de rejeitos produzidos por mês. A FIG. 4 apresenta uma ilustração desse depósito.

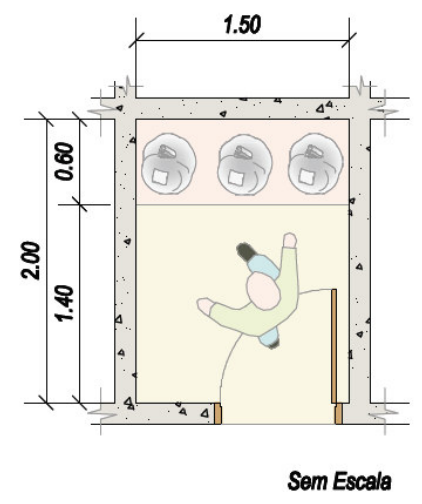

FIGURA 4 - Depósito de rejeitos com $3 \mathrm{~m}^{2}$

Um depósito que tenha uma área de $4 \mathrm{~m}^{2}$, dispondo de duas estantes, ambas com duas prateleiras terá capacidade de armazenar um volume aproximado de $900 \mathrm{~L}$ de rejeitos produzidos por mês. Na FIG. 5 apresenta-se a ilustração desse depósito.

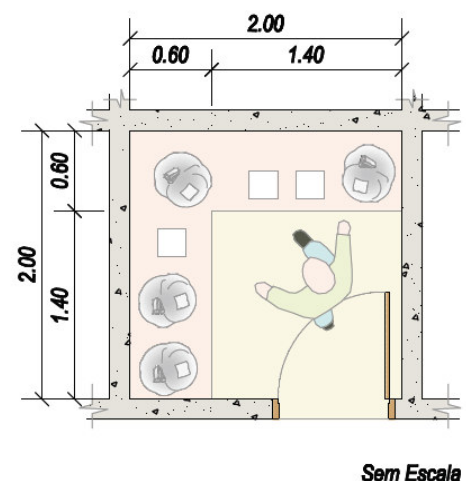

FIGURA 5 - Depósito de rejeitos com área de $4 \mathrm{~m}^{2}$ 
Um depósito que tenha uma área de $9 \mathrm{~m}^{2}$ que disponha de três estantes, todas com três prateleiras terá capacidade de armazenar um volume aproximado de 1900 L de rejeitos produzidos por mês. A FIG. 6 ilustra um depósito com esta área.
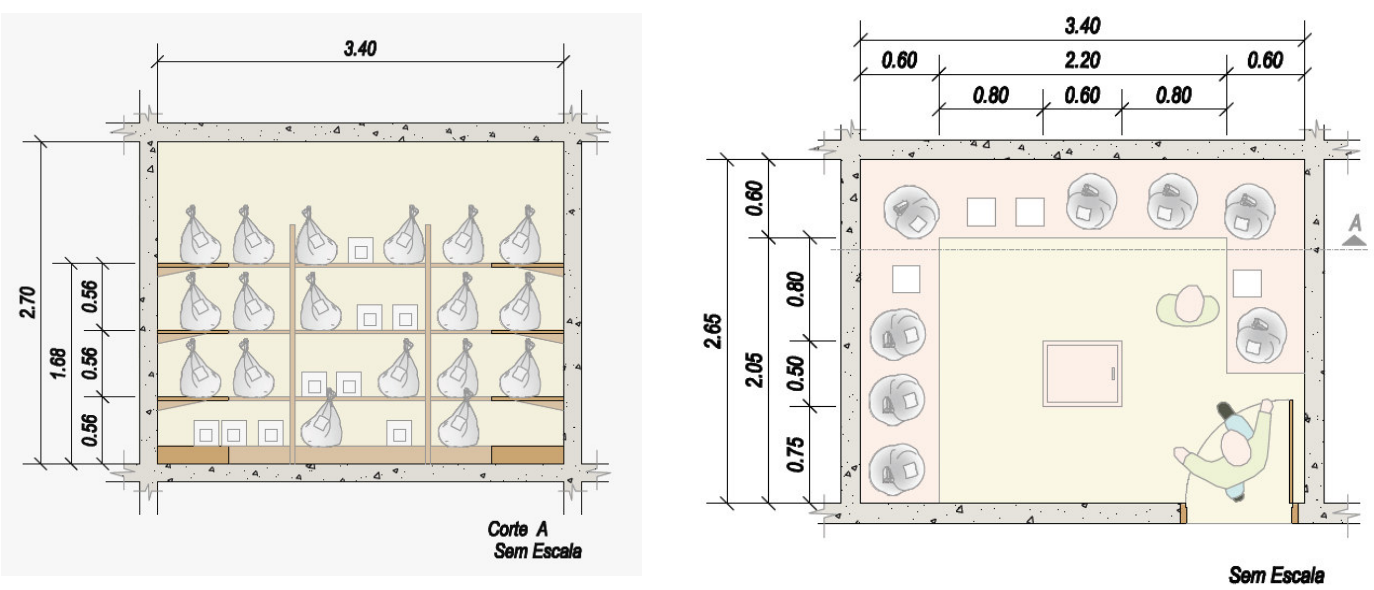

FIGURA 6 - Depósito de rejeitos com área de $9 \mathrm{~m}^{2}$ 


\section{REFERÊNCIAS BIBLIOGRÁFICAS}

[1] COMISSÃO EUROPÉIA. Novo plano energético da União Européia - mais segurança, menos poluição. Disponível em: <http://ec.europa.eu/news/energ/O

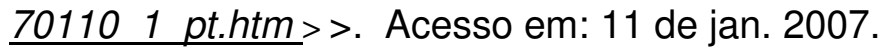

[2]. COMCIENCIA. Energia nuclear custo de uma alternativa. Disponível em: < http://www.comciencia.br/reportagens/nuclear/nuclear01.htm > Acesso em: 10 de fev. 2007

[3] INTERNATIONAL ATOMIC ENERGY AGENCY. Advanced reactors. Disponível em: <http://www.iaea.org/Publications/Factsheets/English/advrea.ht ml>. Acesso em: 8 de abr. 2006.

[4] INTERNATIONAL ATOMIC ENERGY AGENCY. Radiation Technology for Public Health and Safety. Disponível em: <http://www.iaea.org/NewsCenter/New s/2001/10252001 news.shtm . Acesso em: 20 de abr. 2006.

[5] INTERNATIONAL ATOMIC ENERGY AGENCY. Facts about food irradiation. Disponível em: <http://www.iaea.org/nafa/d5/public/foodirradiation.pdts Acesso em: 20 de fev. 2007.

[6] UWE EWERT. Upheaval in industrial radiology. Disponível em: < http://www.ndt.net/article/ecndt02/414/414.htm> Acesso em: 20 de ago. 2006.

[7] COMISSÃO NACIONAL DE ENERGIA NUCLEAR. Gerência de rejeitos radioativos em instalações radioativas. Rio de Janeiro: CNEN-NE-6.05, CNEN, 1985.

[8] AMERICAN INSTITUTE OF PHYSICS. Marie Curie her story in brief. Disponível em: <http://www.aip.org/history/curie/brief/curie-brief.pdts. Acesso em 10 de fev. 2006. 
[9] NATIONAL ATOMIC MUSEUM. Georg von Hevesey. Disponível em:

$<$ http://www.atomicmuseum.com/tour/nm1d2.cfm>. Acesso em 15 de fev. 2006.

[10] SOCIEDAD ESPAÑOLA DE MEDICINA NUCLEAR. M.N. en la actualidad. Disponível em: $<$ http://www.semn.es/publico/mn en la actualidad.html . Acesso em 16 jan. 2006.

[11] HOSPITAL DAS CLÍNICAS DA FACULDADE DE MEDICINA DA UNIVERSIDADE DE SÃO PAULO. Medicina nuclear. Disponível em: $<$ http://www.hcnet.usp.br/inrad/cli radiologica/mn.htm>. Acesso em 20 de ago. 2006.

[12] MACHADOL, A.C.B.; PLEITEZL, V.; TIJEROLL M.C. Usando a antimatéria na medicina moderna. Disponível em: <http://www.scielo.br/scielo.php?script=s ciarttext\&pid=S010247442006000400001\&lng=en\&nrm=iso\&tlng=en> Acesso em 12 de set. 2006.

[13] INTERNATIONAL ATOMIC ENERGY AGENCY, Recomendations for waste disposal of phosphorus-32 and iodine-131 for medical users. IAEA, Vienna, 1951.

[14] SIEMENS. PET \& PET/CT. Disponível em:<http://www.siemens.com.br/t em plates/coluna1.aspx?channel=5239\&parent=2834\&channel pri nivel=2834>. Acesso em 12 de jan. 2007.

[15] COMISSÃO NACIONAL DE ENERGIA NUCLEAR. Entidades autorizadas e registradas. Disponível em: <http://www.cnen.gov.br/seguranca/cons-ent-prof/l stentidades-aut-cert.asp?p ent=mnus. Acesso em 22 de nov. 2007.

[16] SCIENTIFIC ELETRONIC LIBRARY ONLINE. Radiofármacos: produção deverá aumentar com novo acelerador. Disponível em: <http://inovaca.scielo.br/scie lo.php?script=sci arttext\&pid=S1808-23942006000200010\&lng=es\&nrm=iso>. Acesso em $28 \mathrm{de}$ nov. 2007. 
[17] COMISSÃO NACIONAL DE ENERGIA NUCLEAR. Requisitos de radioproteção e segurança para serviços de medicina nuclear. Rio de Janeiro: CNEN-NN-3.05, CNEN, 1996.

[18] COMISSÃO NACIONAL DE ENERGIA NUCLEAR. Aplicações da tecnologia nuclear. Disponível em: <http://www cnen.gov.br/ensino/apostilas/ap lica.pdts Acesso em 22 de nov. 2007.

[19] THRAALL ,J.H.; ZIESSMAN, H.A. Medicina nuclear. 2. ed. Rio de Janeiro, RJ. Guanabara koogan, 2001.

[20] MEDICAL DEVICE LINK. By redesigning a technetium generator to satisfy varying standards, engineers ended up making a safer product. Disponível em: http://www.devicelink.com/emdm/archive/03/10/017.html Acesso em 20 abr. 2007.

[21] INTERNATIONAL ATOMIC ENERGY AGENCY. Nuclear medicine resources manual, Vienna, 2006.

[22] INTERNATIONAL ATOMIC ENERGY AGENCY. Diagnostic nuclear medicine. Disponível em: $<$ http://rpop.iaea.org/RPoP/RPoP/Content/Information For/HealthProfessionals/3 NuclearMedicine/DiagnosticNuclearMedicine.htm>. Acesso em 22 abr. 2007.

[23] Elhendy, A.M.D.; Jeroen J.; Bax, M.D.; Poldermans D. Dobutamine Stress Myocardial Perfusion Imaging in Coronary Artery Disease. Disponível em: $<\underline{h t t}$ p://inm.snmjournals.org/cgi/content/abstract/43/12/1634>. Acesso em 15 abr. 2007.

[24] BAR, R. Y.N; GURALNIK L. Clinical performance of PET/CT in evaluation of cancer: additional value for diagnostic imaging and patient management Disponível em: <http://jnm.snmjournals.org/cgi/content/abstract/44/8/1200>. Acesso em 20 abr. 2007.

[25] INTERNATIONAL ATOMIC ENERGY AGENCY. Radioactive waste management glossary. IAEA, Vienna, 1993. 
[26] COMISSÃO NACIONAL DE ENERGIA NUCLEAR. Licenciamento de instalações radioativas. CNEN-NE-6.02, CNEN, Rio de Janeiro, 1998.

[27] HIROMOTO, G.; DELlAMANO, J. C.; MARUMO, J. T.; ENDO, L. S.; VICENTE, R.; HIRAYAMA, T. Introdução à gerência de rejeitos radioativos. São Paulo, 1999.

[28] SOCIEDAD NUCLEAR ESPAÑOLA, Geración y gestión de residuos de baja radioactividad exención y desclasificasión SNE. Madri, 1994.

[29] QUIMBY, E.H. Disposal of radioactive waste from hospital laboratories. Laboratory Invest. 2(1):49-55, 1953.

[30] Lelli, A. Considerations on the general principles that must be known by those planning a hospital department of nuclear medicine. Minerva Medica, 58(37):1754-61, 1967.

[31] Krieger K.; Van Baalen, M.; Walters, C. Radioactive waste minimization at a large academic medical facility. Health Physics 82(5):S108-10, 2002.

[32] Tripodes, J.G. Minimizing and managing low-level radioactive waste. Med Waste Anal. 2(1):1-5, 1993.

[33] Linins, I.; Klein, R.C.; Gershey, E.L. Management of mixed wastes from biomedical research. Health Physics 61(3):421-6, 1991.

[34] Leidholdt, E.M. Jr.; William, G.E.; McGuire, L.E. A reassessment of radioactive material security in health care and biomedical research. Health Physics 85(2):S15-9, 2003.

[35] Ring, J.; Osborne, F.; Shapiro, J.; Johnson, R. Radioactive waste management at a large university and medical research complex. Health Physics 65(2):193-9, 1993.

[36] ARAÚJO, E. B. Produção de radiofármacos no ipen. Disponível em: <http://www.anvisa.gov.br/divulga/noticias/2006/071106 3 ipen.pdf >. Acesso em: 19 de jan. 2007 
[37] MINISTÉRIO DA CIENCIA E DA TECNOLOGIA. Primeiro acelerador circular de partículas do país faz 30 anos. Disponível em: $<$ http://agenciact.mct.gov.br/index.php/content/view/22635.html>. Acesso em: 19 de jan. 2007

[38] MINISTÉRIO DA CIENCIA E DA TECNOLOGIA. Simpósio reúne especialistas em medicina nuclear. Disponível em: $<$ http://agenciact.mct.gov.br/index.php/content/view/44525.html>. Acesso em: 19 de jan. 2007

[39] INTERNATIONAL ATOMIC ENERGY AGENCY, International Nuclear Information System. Disponível em:< http://www.iaea.org/inisnkm/> Acesso em: 19 de dez. 2006).

[40] EMPRESA NACIONAL DE RESIDUOS RADACTIVOS, Búsqueda.

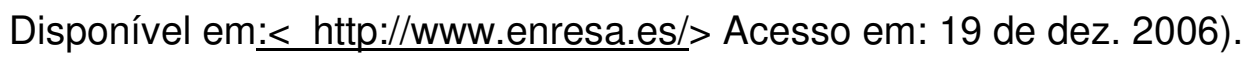

[41] INTERNATIONAL ATOMIC ENERGY AGENCY. Management of radioactive waste from the use of radionuclides in medicine, IAEA, Vienna, 2000. (IAEATECDOC-1183)

[42] INTERNATIONAL ATOMIC ENERGY AGENCY. Radiological protection for medical exposure to ionizing radiation. IAEA, VIENNA, 2002 (Safety Standards Series RS-G-1.5)

[43] COMISSÃO NACIONAL DE ENERGIA NUCLEAR. Transporte de Materiais Radioativos. Rio de Janeiro: CNEN-NE-5.01, 1998.

[44] INTERNATIONAL ATOMIC ENERGY AGENCY. Applyng radiation safety standars in nuclear medicine. VIENNA, 2005 (Safety Reports 40)

[45] COMISSÃO NACIONAL DE ENERGIA NUCLEAR. Serviços de radioproteção. Rio de Janeiro: CNEN-NE-3.02, CNEN, 1988.

[46] COMISSÃO NACIONAL DE ENERGIA NUCLEAR. Diretrizes básicas de radioproteção. Rio de Janeiro: CNEN-NN-3.01, CNEN, 2005. 